\title{
PIGMENTED EUGLENOPHYTES OF THE GENERA EUGLENA, EUGLENARIA, LEPOCINCLIS, PHACUS AND MONOMORPHINA FROM THE SOUTHEASTERN UNITED STATES
}

\author{
KonRad WoŁowski ${ }^{1}$, MaŁgorzata PoniewoziK \& Patricia L. WaLne $\uparrow$
}

\begin{abstract}
The biogeography and taxonomy of euglenophytes from the southeastern United States were studied in material from lakes, ponds and rivers of Alabama, Georgia, Kentucky, Mississippi, North Carolina and Tennessee. The 68 taxa found, 26 of which are new for this region, belong to the genera Euglena (26 taxa), Euglenaria (2), Lepocinclis (13), Phacus (25) and Monomorphina (2). The taxa occurred at low density, sometimes as a single specimen. Euglenophyte diversity was highest in ponds; rivers had the fewest taxa. Euglenophytes were present in most plankton samples.
\end{abstract}

Key words: biogeography, Euglenophyceae, Euglena, Euglenaria, Lepocinclis, Monomorphina, Phacus, taxonomy

Konrad Wolowski, Department of Phycology, W. Szafer Institute of Botany, Polish Academy of Sciences, Lubicz 46, 31-512, Poland; e-mail: k.wolowski@botany.pl

Matgorzata Poniewozik, Department of Botany and Hydrobiology, The John Paul II Catholic University of Lublin, Konstantynów 1H, 20-708 Lublin, Poland; e-mail: gonium@kul.pl

Patricia L. Walne, Department of Botany, University of Tennessee, Knoxville, U.S.A.

\section{INTRODUCTION}

The extensive research done on euglenophytes in the United States has largely dealt with biochemical, molecular and phylogenetic aspects, but there have also been quite a number of floristic studies on this group of algae. Floristic studies on the southeastern United States giving records of euglenophytes include the following: Bovee (1960), Lackey and Lackey (1967), McCoy (1967), Patrick et al. (1967), Woodson (1969), Dillard and Crider (1970), Whitford (1979), Zakryś and Walne (1994) and Wołowski and Walne (1997, 2007). Dillard (2000) compiled 246 euglenoid species reported from this region. Rosowski (2003) summarized information about photosynthetic euglenoids in North America as a whole, but gave descriptions for only 10 photosynthetic euglenoid genera, together with detailed bibliographic information. A study initiated by Walne and carried out by Zakryś and Wołowski (Zakryś \& Walne 1994; Wołowski \& Walne 1997, 2007) gave more

\footnotetext{
1 Corresponding author
}

data on euglenophyte diversity, focussing on green euglenophytes in the southeastern United States Altogether 56 taxa were described and illustrated with original drawings. These taxa belonged to Euglena (together with an identification key for those taxa), Eutreptia, Lepocinclis, Phacus and Strombomonas. The drawings show particular elements of cell structure in detail. Wołowski and Walne (2007) dealt with Trachelomonas (63 taxa) and gave more information about Strombomonas (5 taxa) from this region; 26 taxa were new for the southeastern United States. In addition to detailed descriptions of taxa and physical and chemical data, that paper provided extensive SEM and LM micrographs with details of the morphology of Trachelomonas and Strombomonas loricae. Colorless Euglenophyceae were included in another paper (Wołowski \& Walne 1997), with 22 taxa from the following genera: Anisonema, Astasia, Cyclidiopsis, Entosiphon, Gyropaigne, Hyalophacus, Khawkinea, Menoidium, Peranemopsis, Petalomonas, Pseudoperanema and Rhabdomonas. 
All were accompanied by original drawings and some also by micrographs.

The present paper reports similar data for $E \mathbf{E}$ glena, new Euglenaria, Lepocinclis, Phacus and Monomorphina, to supplement the research on other euglenophytes from the southeastern United States, with information about cosmopolitan taxa and others not previously presented for this region. Only 16 of them were described as common or very common by Dillard (2000). The other 52 are new or rare for this region.

\section{MATERIALS AND METHODS}

The research was done during a 7-month period in 1994. Samples were collected from 59 sites, including lakes, farm and fish ponds, and rivers in six states of the southeastern United States (Alabama, Georgia, Kentucky, Mississippi, North Carolina, Tennessee) (Fig. 1). The samples were obtained from different microhabitats: surface waters, bottom (mud and sediments), water from squeezed mosses and vascular plants. The samples were kept cool during transport to the laboratory and taxonomic studies. Taxonomic identification, measurements, photographs, drawings and descriptions were made from living material. For microscopic observation a Zeiss research microscope fitted with bright-field, Nomarski and phase-contrast optics, and Cambridge Stereoscan 300 (SEM) was used. Micrographs were taken with an Olympus automatic photographic system, and drawings were made using a camera lucida system. Water physicochemistry was measured directly in the field and include $\mathrm{pH}$, specific conductance, temperature and oxidation/reduction potential. All measurements were

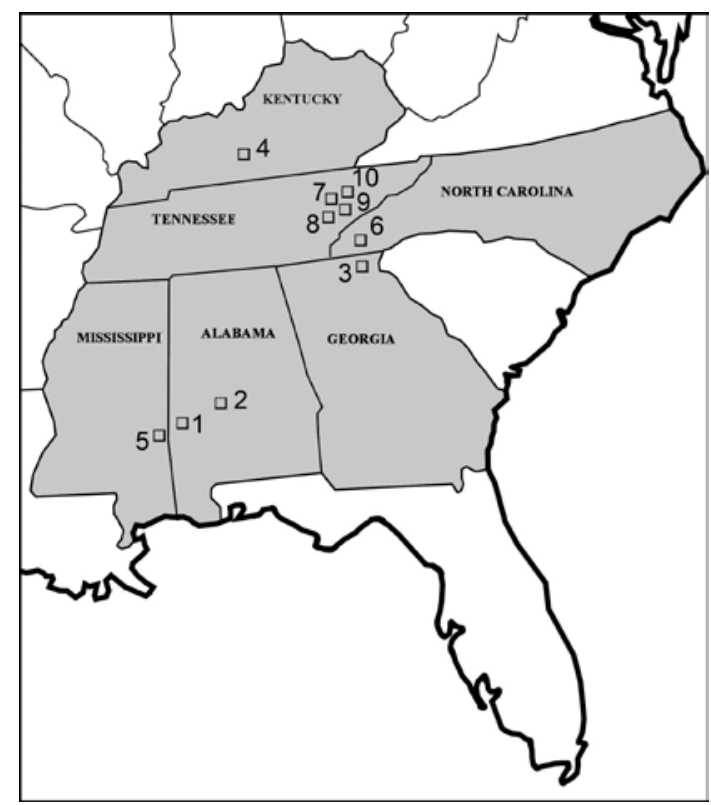

Fig. 1. Location of the collection sites. 1 - Sumter County, 2 - Tuscaloosa Co., 3 - Sky Valley, 4 - Warren Co., 5 - Lauderdale Co., 6 - Macon Co., 7 - Anderson Co., 8 - Blount Co., 9 - Knox Co., 10 - Union Co.

made with a portable Hanna Water Tester and the results are given in Table 1.

\section{RESULTS}

We determined 68 taxa. Each one is briefly described and illustrated with original drawings and in some cases by LM micrographs. The

Table 1. Physicochemical parameters of water (ranges of values) at sampling localities. T - temperature, EC - electrolytic conductivity, ORP - oxidation/reduction potential.

\begin{tabular}{|c|c|c|c|c|}
\hline Locality & $\mathrm{pH}$ & $\mathrm{T}\left[{ }^{\circ} \mathrm{C}\right]$ & $\mathrm{EC}[\mathrm{mS} / \mathrm{cm}]$ & $\mathrm{ORP}[\mathrm{mV}]$ \\
\hline Alabama, Sumter County & $8.5-9.8$ & $31.0-35.0$ & $0.21-2.27$ & $9-110$ \\
\hline Alabama, Tuscaloosa County & $5.7-9.3$ & $27.0-33.5$ & $0.05-0.13$ & $4-170$ \\
\hline Georgia, Sky Valley & 7.3 & 25.5 & 0.23 & 136 \\
\hline Kentucky, Warren County & $5.6-9.3$ & $14.7-28.2$ & $0.15-0.93$ & $142-169$ \\
\hline Mississippi, Lauderdale County & $6.0-8.0$ & $28.6-34.9$ & $0.17-0.90$ & $19-184$ \\
\hline North Carolina, Macon County & $5.9-7.0$ & $16.0-19.0$ & $0.18-0.27$ & $100-169$ \\
\hline North Carolina, Anderson County & $6.6-7.2$ & $21.0-22.3$ & $0.17-0.20$ & $232-233$ \\
\hline Tennessee, Blount County & 9.9 & 10.0 & - & - \\
\hline Tennessee, Knox County & $9.2-9.8$ & $10.0-12.0$ & - & - \\
\hline Tennessee, Union County & 7.5 & 22.6 & 2.02 & 1 \\
\hline
\end{tabular}


descriptions are completed with information on habitat $(\mathrm{dl}$ - decaying leaves, gm - green mat, $\mathrm{m}$ - bottom mud, $\mathrm{n}$ - neuston, $\mathrm{p}$ - plankton, $\mathrm{pb}$ - peat bog, sq - squeezed mosses or vascular plants, ss - surface scum); that information is given in Table 2 .

Taxonomy generally follows Pringsheim
(1956), Leedale (1967) and Wołowski (1998), with changes related to photosynthetic euglenoids from Milanowski et al. (2001, 2006), Marin et al. (2003), Brosnan et al. (2005), Wołowski and Hindák (2005), Triemer and Farmer (2007), Ciugulea and Triemer (2010), Linton et al. (2010) and Wołowski (2011).

Table 2. List of Euglena Ehrenb., Euglenaria Karnkowska \& E. W. Linton, Lepicinclis Perty, Phacus Dujard. and Monomorphina Mereschkovski taxa found in the southeastern United States. AL - Alabama, GA - Georgia, KY - Kentucky, MS - Mississippi, NC - North Carolina, TN - Tennessee; $\mathrm{dl}$ - decaying leaves, gm - green mat, $\mathrm{m}$ - bottom mud, $\mathrm{n}-\mathrm{neuston}, \mathrm{p}-\mathrm{plankton}$, $\mathrm{pb}$ - peat bog, sq - squeezed mosses or vascular plants, ss - surface scum.

\begin{tabular}{|c|c|c|c|c|c|c|}
\hline Taxon & $\mathrm{AL}$ & GA & KY & MS & $\mathrm{NC}$ & $\mathrm{TN}$ \\
\hline Euglena cf. gaumei & gm & . & . & . & . & . \\
\hline E. antefossa & $\mathrm{p}$ & . & . & . & $\mathrm{m}$ & . \\
\hline E. pavlovskoensis & $\mathrm{gm}, \mathrm{m}$ & . & . & . & . & . \\
\hline E. limnophila & . & . & $\mathrm{sq}$ & $\mathrm{p}$ & . & . \\
\hline E. limnophila var. swirenkoi & . & . & $\mathrm{sq}$ & . & . & . \\
\hline E. tuberculata & . & . & . & . & $\mathrm{m}$ & . \\
\hline E. geniculata & . & $\mathrm{sq}, \mathrm{n}$ & . & . & $\mathrm{b}$ & . \\
\hline E. cuneata & $\mathrm{pb}$ & . & . & . & . & . \\
\hline E. tristella & . & . & . & . & . & $\mathrm{p}$ \\
\hline E. viridis & $\mathrm{p}, \mathrm{ss}$ & . & . & . & $\mathrm{b}$ & $\mathrm{p}$ \\
\hline E. stellata & . & . & . & . & $\mathrm{b}$ & . \\
\hline E. hemichromata & . & $\mathrm{n}$ & . & $\mathrm{m}, \mathrm{n}, \mathrm{m}, \mathrm{p}$ & $\mathrm{b}$ & . \\
\hline E. proxima & . & . & $\mathrm{sq}$ & . & . & $\mathrm{p}$ \\
\hline E. ehrenbergii & $\mathrm{p}$ & . & . & . & . & $\mathrm{m}$ \\
\hline E. cf. ettlii & . & . & . & . & . & $\mathrm{m}$ \\
\hline E. agilis & $\mathrm{gm}$ & . & . & $\mathrm{m}, \mathrm{n}$ & . & $\mathrm{p}$ \\
\hline E. chlamydophora & . & . & $\mathrm{n}$ & . & . & . \\
\hline E. granulata & $\mathrm{p}$ & . & . & . & . & . \\
\hline E. sociabilis & . & $\mathrm{n}$ & . & . & . & . \\
\hline E. velata & . & . & . & . & $\mathrm{m}$ & . \\
\hline E. obtusa & . & . & $\mathrm{m}$ & $\mathrm{m}, \mathrm{n}$ & . & . \\
\hline E. splendens & $\mathrm{p}$ & . & $\mathrm{m}$ & $\mathrm{dl}$ & . & . \\
\hline E. satelles & . & . & $\mathrm{m}$ & . & . & . \\
\hline E. vermicularis & . & . & . & . & $\mathrm{p}$ & . \\
\hline E. vagans & . & . & $\mathrm{m}$ & . & . & . \\
\hline E. mutabilis & $\mathrm{gm}, \mathrm{p}$ & $\mathrm{sq}$ & . & . & . & $\mathrm{p}$ \\
\hline Euglenaria anabaena & . & . & $\mathrm{n}$ & . & . & . \\
\hline E. caudata var. caudata & $\mathrm{p}, \mathrm{m}$ & $\mathrm{n}$ & $\mathrm{m}$ & $\mathrm{m}, \mathrm{p}$ & $\mathrm{m}$ & . \\
\hline Lepocinclis ovum var. ovum & $\mathrm{n}$ & . & . & . & . & $\mathrm{m}$ \\
\hline L. texta var. texta & $\mathrm{p}, \mathrm{m}$ & . & $\mathrm{p}$ & $\mathrm{m}, \mathrm{n}, \mathrm{dl}, \mathrm{p}$ & $\mathrm{p}$ & $\mathrm{m}, \mathrm{p}$ \\
\hline L. salina fo. obtusa & $\mathrm{m}$ & . & . & . & . & . \\
\hline L. cylindrica & . & . & . & $\mathrm{m}$ & . & . \\
\hline L. steinii & . & . & . & . & . & $\mathrm{m}$ \\
\hline L. marssonii & . & . & $\mathrm{m}$ & . & . & . \\
\hline L. acus & $\mathrm{p}, \mathrm{gm}$ & . & . & $\mathrm{p}$ & . & . \\
\hline
\end{tabular}


Table 2. Continued.

\begin{tabular}{|c|c|c|c|c|c|c|}
\hline Taxon & $\mathrm{AL}$ & GA & KY & MS & $\mathrm{NC}$ & $\mathrm{TN}$ \\
\hline L. spirogyroides & $\mathrm{p}, \mathrm{gm}, \mathrm{m}$ & . & . & $\mathrm{p}$ & . & $\mathrm{p}$ \\
\hline L. fusca & $\mathrm{gm}$ & . & . & . & . & . \\
\hline L. oxyuris & $\mathrm{gm}$ & . & . & $\mathrm{p}$ & $\mathrm{m}$ & . \\
\hline L. oxyuris var. maior & . & . & $\mathrm{m}$ & . & . & $\mathrm{p}$ \\
\hline L. oxyuris fo. lata & . & . & . & . & $\mathrm{m}$ & . \\
\hline L. tripteris & $\mathrm{gm}, \mathrm{m}, \mathrm{p}$ & . & $\mathrm{m}$ & . & $\mathrm{sq}$ & . \\
\hline Phacus parvulus & . & . & . & . & . & $\mathrm{m}$ \\
\hline Ph. pusillus & . & . & . & . & . & $\mathrm{m}$ \\
\hline Ph. dangeardii & . & . & . & . & . & $\mathrm{m}$ \\
\hline Ph. fominii & $\mathrm{gm}$ & . & . & . & . & . \\
\hline Ph. acuminatus & $\mathrm{m}$ & . & . & . & . & $\mathrm{gm}$ \\
\hline Ph. oscillans & . & . & . & . & . & $\mathrm{p}$ \\
\hline Ph. undulatus & $\mathrm{m}$ & . & . & . & . & . \\
\hline Ph. unguis & $\mathrm{gm}$ & . & . & . & . & $\mathrm{m}$ \\
\hline Ph. orbicularis & $\mathrm{p}$ & . & $\mathrm{m}$ & $\mathrm{m}$ & . & $\mathrm{gm}, \mathrm{p}$ \\
\hline Ph. pleuronectes & gm, n-gm & . & . & $\mathrm{m}, \mathrm{dl}$ & . & $\mathrm{m}$ \\
\hline Ph. ankylonoton & . & . & . & . & . & $\mathrm{m}$ \\
\hline Ph. hamelii & . & . & . & $\mathrm{m}$ & . & . \\
\hline Ph. triqueter & $\mathrm{gm}, \mathrm{sq}$ & . & $\mathrm{p}$ & . & . & $\mathrm{m}$ \\
\hline Ph. alatus & . & . & . & $\mathrm{p}$ & . & . \\
\hline Ph. curvicauda & . & . & $\mathrm{p}$ & $\mathrm{p}$ & . & $\mathrm{m}$ \\
\hline Ph. raciborskii & $\mathrm{gm}$ & . & . & . & . & . \\
\hline Ph. longicauda & $\mathrm{p}$ & . & . & $\mathrm{p}$ & $\mathrm{p}$ & $\mathrm{m}$ \\
\hline Ph. longicauda var. attenuata & $\mathrm{p}$ & . & . & . & . & . \\
\hline Ph. longicauda var. rotunda & $\mathrm{p}$ & . & . & . & . & . \\
\hline Ph. circumflexus & $\mathrm{p}$ & . & . & . & . & . \\
\hline Ph. ephippion & . & . & $\mathrm{sq}$ & . & . & . \\
\hline Ph. helikoides & . & . & . & $\mathrm{p}$ & . & . \\
\hline Ph. smulkowskianus & . & . & . & . & . & $\mathrm{m}$ \\
\hline Ph. monilatus & $\mathrm{p}$ & . & . & . & $\mathrm{p}$ & . \\
\hline$P h$. sp. & $\mathrm{gm}$ & . & . & . & . & . \\
\hline Monomorphina pyrum & $\mathrm{gm}$ & . & . & . & . & . \\
\hline M. splendens & $\mathrm{m}$ & . & $\mathrm{m}$ & . & . & . \\
\hline
\end{tabular}

\section{TAXONOMICAL DESCRIPTIONS}

\section{Euglena Ehrenb. 1838}

Euglena cf. gaumei P. Allorge \& M. Lefèvre 1931

Fig. 2

Cell $140 \mu \mathrm{m}$ long and $14 \mu \mathrm{m}$ wide, cylindrical to crescent-shaped, ended with hyaline cauda at posterior end. Cell with numerous small chloroplasts and two large paramylon bodies. Pellicle longitudinally striated.
SITES: Alabama, Tuscaloosa County, small duck pond in University of Alabama area.

OCCURRENCE. Earlier reported from Florida by McCoy (1967)

Euglena antefossa L. P. Johnson 1944

Fig. 3

Cell $162.5 \mu \mathrm{m}$ long and $20 \mu \mathrm{m}$ wide with $30 \mu \mathrm{m}$ long cauda. Cell long, cylindrical, with longitudinally striated pellicle. Chloroplasts small and plate-shaped; paramylon grains on both sides of nucleus. 
SiTeS: Alabama, Tuscaloosa County, Butterfield catfish pond 22; North Carolina, Macon County, Patton and White Roads pond.

OCCURRENCE. Earlier reported from Alabama by Zakryś and Walne (1994).

NoTE. The cell is similar to Lepocinclis oxyuris but is more elongated and not twisted (as L. oxyuris is).

Euglena pavlovskoensis (Elenkin \& Poljansky)

T. G. Popova 1951

Fig. 4

Euglena intermedia var. pavlovskoensis Elenkin \& Poljansky 1938

Cells 77-95 $\mu \mathrm{m}$ long and 10-13 $\mu \mathrm{m}$ wide. Cells cylindrical, quite often bent; posterior end gradually tapering to narrow hyaline tail. Pellicle finely spirally striated. Central nucleus with two large oval-shaped paramylon grains; chloroplasts small and numerous. Flagellum 1/2 the length of cell.

SITES: Alabama, Sumter County, Nixon's pond; Alabama, Sumter County, Livingston University duck pond; Alabama, Tuscaloosa County, small duck pond in University of Alabama area.

Note. The specimens are similar in cell organization and dimensions to Lepocinclis oxyuris and Euglena antefossa, but these specimens are not twisted (as L. oxyuris is) and are considerably smaller than specimens of E. antefossa.

Euglena limnophila Lemmerm. $1913 \quad$ Fig. 5

Cell $70 \mu \mathrm{m}$ long and $12 \mu \mathrm{m}$ wide, cylindrical to fusiform. Cell with cauda $15 \mu \mathrm{m}$ long at posterior end, which is clearly marked, sharp and hyaline.

SITES: Kentucky, Warren County, spring; Mississippi, Lauderdale County, Kewanee Road, Beaver Pond.

OCCURRENCE. Earlier reported from Georgia by Patrick et al. (1967).

Note. Recently classified also as Phacus limnophila (Lemmerm.) E. W. Linton \& Karnkowska (Ciugulea \& Triemer 2010).
Euglena limnophila var. swirenkoi T. G. Popova 1955

Fig. 6a-d

Euglena swirenkoi Arnoldi 1922, E. limnophila var. minor Drezep. 1925

Cell $41 \mu \mathrm{m}$ long, $10 \mu \mathrm{m}$ wide and $7 \mu \mathrm{m}$ thick, fusiform or bent with sharp elongated cauda at posterior end.

SITES: Kentucky, Warren County, spring.

Note. Recently classified as Phacus limnophila (Lemmerm.) E. W. Linton \& Karnkowska (Ciugulea \& Triemer 2010).

\section{Euglena tuberculata Svirenko 1915}

Fig. 7

Cells 45.0-45.8 $\mu \mathrm{m}$ long and 17.0-17.5 $\mu \mathrm{m}$ wide. Cells with long sharp tail-piece. Sides of cells folded; in cells are very numerous ovalshaped paramylon grains, densely crammed, which cover the chloroplasts, make the sides of the cell appear folded, or even form delicate swellings on the cell surface.

SiTES: North Carolina, Macon County, Patton and White Roads pond.

Euglena geniculata Dujard. 1841 Figs 8 \& 71

Cells 57.5-90.0 $\mu \mathrm{m}$ long and 10-15 $\mu \mathrm{m}$ wide, fusiform to cylindrical fusiform; each cell slightly narrowing at posterior end. Cells possess two starshaped chloroplasts on both sides of centrally located nucleus.

SITES: Georgia, Sky Valley, Tahoe Road, lake; North Carolina, Macon County, Patton Road Golf Creek.

OCCURRENCE. Earlier reported from Georgia by Patrick et al. (1967) and from Alabama and Tennessee by Zakryś and Walne (1994).

Euglena cuneata E. G. Pringsh. 1956

Fig. 9

Cells 50-52 $\mu \mathrm{m}$ long and 22.5-25.0 $\mu \mathrm{m}$ wide, broadly cylindrical, rounded at both anterior and posterior ends; one large star-shaped chloroplast filling cell interior. 
SITES: Alabama, Sumter County, Veterans of Foreign Wars, peat bog.

Euglena tristella S. P. Chu 1947 Figs $10 \& 72$

Cell $77.5 \mu \mathrm{m}$ long and $20 \mu \mathrm{m}$ wide, broadly fusiform, tapering at posterior end and rounded at anterior end. Specimens have three star-shaped chloroplasts similar to those in E. geniculata cells. Each chloroplast possesses a central pyrenoid group.

SITES: Tennessee, Union County, Brock Road, farm pond near barn.

Euglena viridis Ehrenb. 1838

Figs $11 \& 73$

Cells 42.5-48.5 $\mu \mathrm{m}$ long and 10-15 $\mu \mathrm{m}$ wide, fusiform to broadly fusiform, ended in tapering tail-piece. Cells widest at midlength of cell, forming characteristic bulge there.

Sites: Alabama, Tuscaloosa County, Butterfield catfish pond 21; Alabama, Tuscaloosa County, Butterfield catfish pond 22; North Carolina, Macon County, Patton Road Golf Creek; Tennessee, Knox County, fish pond.

OCCURRENCE. Common in southeastern United States (Dillard 2000).

\section{Euglena stellata Mainx 1926}

Fig. 12

Cells 35-40 $\mu \mathrm{m}$ long and 15.0-17.5 $\mu \mathrm{m}$ wide, fusiform with rounded anterior end, posterior end gradually narrowing; one star-shaped chloroplast in upper part of cell.

SITES: North Carolina, Macon County, Patton Road Golf Creek.

OCCURRENCE. Earlier reported from Tennessee by Zakryś and Walne (1994).

\section{Euglena hemichromata Skuja 1948}

Figs $13 \& 74$

Cells 65-89 $\mu \mathrm{m}$ long and 15.0-20.5 $\mu \mathrm{m}$ wide, broadly fusiform with gently narrowing posterior end; numerous small chloroplasts.

SITES: Georgia, Sky Valley, Tahoe Road, lake;
Mississippi, Lauderdale County, Toom Suba Creek; Mississippi, Lauderdale County, Kewanee pond; Mississippi, Lauderdale County, Kewanee Road, ditch; Mississippi, Lauderdale County, Toom Suba Creek; North Carolina, Macon County, Patton Road Golf Creek.

OCCURRENCE. Earlier reported from Alabama, North Carolina and Tennessee by Zakryś and Walne (1994).

Euglena proxima P. A. Dang. 1901

Fig. 14

Cell $50 \mu \mathrm{m}$ long and $13 \mu \mathrm{m}$ wide, broadly fusiform, slightly narrowed at anterior end and tapering at posterior end. Nucleus in central part of cell; small discoid chloroplasts.

SITES: Kentucky, Warren County, Jackson Orchard, big pond; Tennessee, Knox County, fish pond.

OCCURRENCE. Common in southeastern United States (Dillard 2000).

Euglena ehrenbergii G. A. Klebs 1883

Figs $15 a, b \& 75$

Cells 135-180 $\mu \mathrm{m}$ long and 10-30 $\mu \mathrm{m}$ wide, cylindrical, strongly elongated and flattened; some slightly twisted, intensely euglenoid movements. Nucleus usually in lower part of cell; very numerous small chloroplasts; paramylon grain in the form of a long rod.

Sites: Alabama, Sumter County, W. Suffolk pond; Tennessee, Union County, Malueg Farm, upper pond.

OCCURRENCE. Common in southeastern United States (Dillard 2000).

Euglena cf. ettlii Wołowski 1993

Fig. 16

Cells 39-40 $\mu \mathrm{m}$ long and $17.5 \mu \mathrm{m}$ wide, broadly fusiform with one axial chloroplast having uneven edges. Nucleus in center of cell; paramylon grains small, oval and not numerous.

Sites: Tennessee, Knox County, puddle in Cherokee Park. 

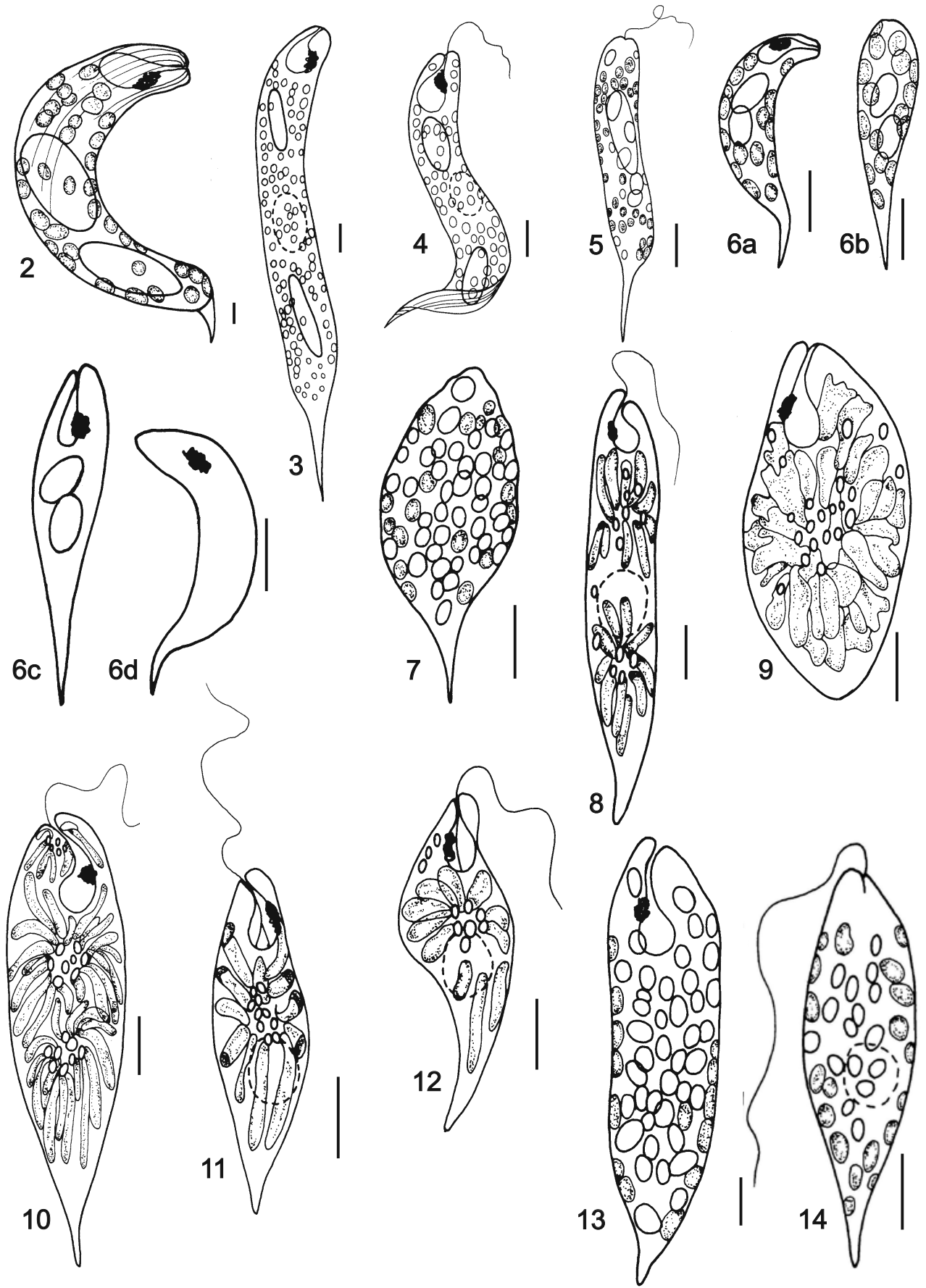

Figs 2-14. 2 - Euglena cf. gaumei P. Allorge \& M. Lefèvre, 3 - E. antefossa L. P. Johnson, 4 - E. pavlovskoensis (Elenkin \& Poljansky) T. G. Popova, 5 - E. limnophila Lemmerm., 6a, b, c, d - E. limnophila var. swirenkoi T. G. Popova, 7 - E. tuberculata Svirenko, 8 - E. geniculata Dujard., $9-$ E. cuneata E. G. Pringsh., $10-$ E. tristella S. P. Chu, $11-$ E. viridis Ehrenb., 12 - E. stellata Mainx, $13-$ E. hemichromata Skuja, $14-$ E. proxima P. A. Dang. Scale bars $=10 \mu \mathrm{m}$. 
Euglena agilis H. J. Carter 1856 Figs 18 \& 80

Cells 22.0-27.5 $\mu \mathrm{m}$ long and 7.5-12.5 $\mu \mathrm{m}$ wide, short fusiform with two elongated chloroplasts, each with double pyrenoid.

SITES: Alabama, Sumter County, Nixon's pond; Mississippi, Lauderdale County, Kewanee pond; Tennessee, Union County, Brock Road, farm pond near barn.

OCCURRENCE. Common in southeastern United States (Dillard 2000).

\section{Euglena chlamydophora Mainx 1926 Fig. 19}

Cell $40.5 \mu \mathrm{m}$ long and $11 \mu \mathrm{m}$ wide, broadly fusiform, narrowing at anterior and posterior ends; emergent flagellum 1/2 the length of cell. Chloroplasts small and not numerous; a few paramylon bodies in the form of oval grains.

SITES: Kentucky, Warren County, Jackson Orchard, big pond.

OCCURRENCE. Earlier reported from Georgia by Patrick et al. (1967), North Carolina by Morris et al. (1977).

Euglena polymorpha P. A. Dang. 1901

Fig. 21a, b

Cells 59-62 $\mu \mathrm{m}$ long and 20-29 $\mu \mathrm{m}$ wide, broadly oval with long tail-piece. Flagellum longer than cell length. Chloroplasts with irregular edges, each with double pyrenoids.

SITES: Georgia, Sky Valley, Tahoe Road, lake; Mississippi, Lauderdale County, Cobb's pond.

OCCURRENCE. Common in southeastern United States (Dillard 2000).

Euglena granulata (G. A. Klebs) F. Schmitz 1884

Fig. 22

Euglena velata var. granulata G. A. Klebs 1883

Cell $78 \mu \mathrm{m}$ long and $15 \mu \mathrm{m}$ wide, cylindrical, ended with clearly formed hyaline cauda. Chloroplasts with small pyrenoids; nucleus in cell center.
Sites: Alabama, Sumter County, Nixon's pond.

OCCURRENCE. Earlier reported from Georgia by Patrick et al. (1967).

NOTE. The cell is similar to E. caudata representatives but its shape is clearly cylindrical while E. caudata is spindle-shaped to broadly fusiform.

Euglena sociabilis P. A. Dang. 1901

Figs $23 \& 76$

Cell $85 \mu \mathrm{m}$ long and $15 \mu \mathrm{m}$ wide, fusiform, anterior end finely elongated and rounded, posterior end tapering to slender cauda. Chloroplasts with elongated lobes arranged below periplast.

SiTES: Georgia, Sky Valley, Tahoe Road, lake.

OCCURRENCE. Common in southeastern United States (Dillard 2000).

Euglena velata G. A. Klebs 1883

Fig. 24

Cell $90.0 \mu \mathrm{m}$ long and $18.5 \mu \mathrm{m}$ wide; numerous elongated chloroplasts with double pyrenoids. Periplast slightly spirally striated; central nucleus, paramylon bodies in the form of circular or oval grains.

SITES: North Carolina, Macon County, Patton and White Roads pond.

OCCURRENCE. Earlier reported from Tennessee by Lackey $(1942,1958)$, North Carolina by Smith (1958) and Alabama by Zakryś and Walne (1994).

Euglena obtusa F. Schmitz 1884

Fig. 25

Cells 125.0-137.5 $\mu \mathrm{m}$ long and 31.5-37.5 $\mu \mathrm{m}$ wide, broadly oval to slightly elongated, anterior and posterior ends rounded. Pellicle spirally striated; nucleus in lower part of cell; chloroplasts small and very numerous. Euglenoid movements creeping.

SITES: Kentucky, Warren County, Campgrounds 


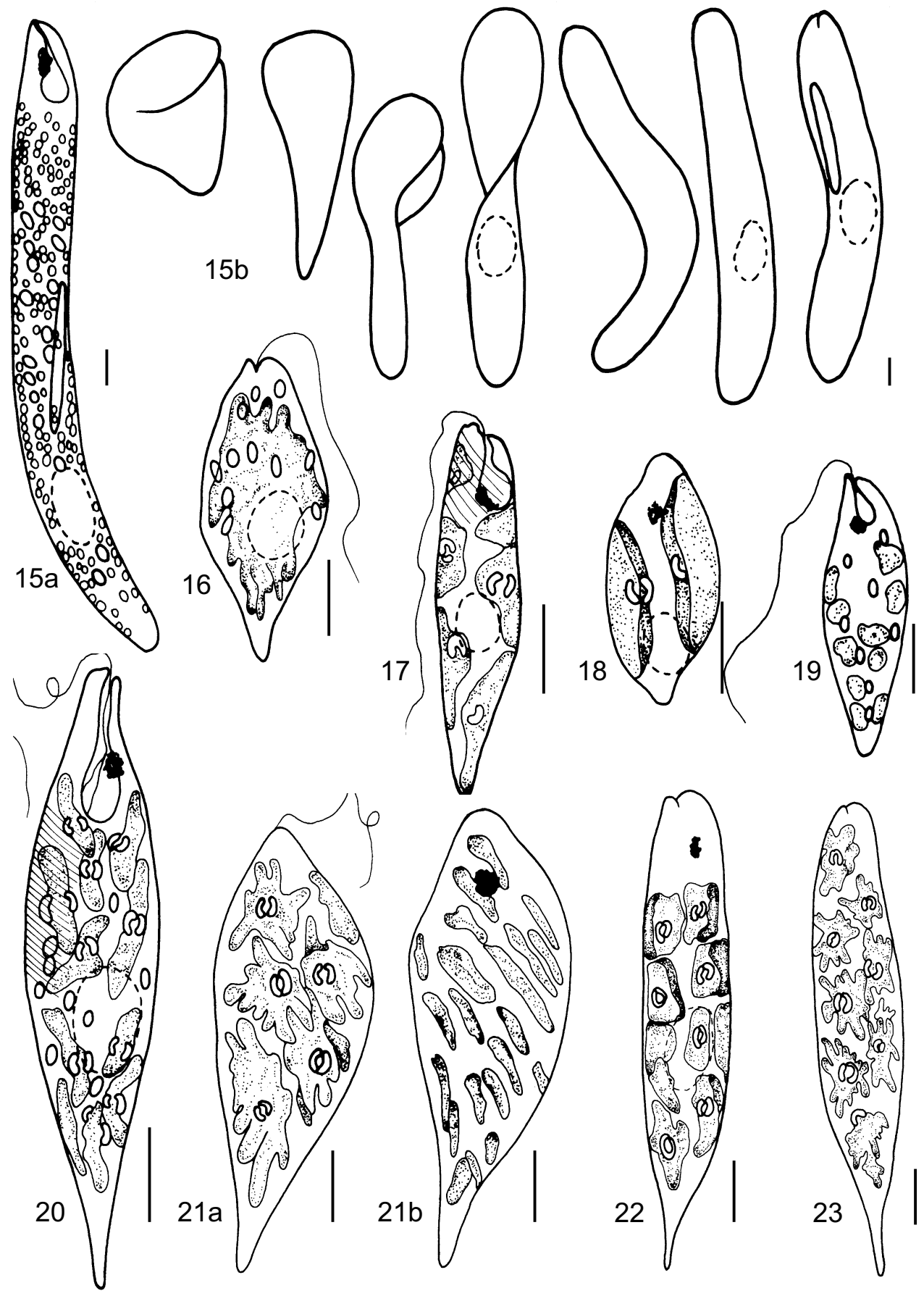

Figs 15-23. 15a, b - Euglena ehrenbergii G. A. Klebs, b - metabolic movement, 16 - E. cf. ettlii Wołowski, 17 - Euglenaria anabaena (Mainx) Karnkowska \& E. W. Linton, 18 - Euglena agilis H. J. Carter, 19 - E. chlamydophora Mainx, 20 - Euglenaria caudata var. caudata (Hüber) Karnowska \& E. W. Linton, 21a, b - Euglena polymorpha P. A. Dang., 22 - E. granulata (G. A. Klebs) F. Schmitz, $23-$ E. sociabilis P. A. Dang. Scale bars $=10 \mu \mathrm{m}$. 
of America pond; Mississippi, Lauderdale County, Kewanee pond.

Euglena splendens P. A. Dang. 1901

Figs $26 \& 77$

Cells 67-95 $\mu \mathrm{m}$ long and 27-32 $\mu \mathrm{m}$ wide, broadly oval to broadly fusiform, anterior end finely narrowing and rounded, posterior end with small projection.

Sites: Alabama, Tuscaloosa County, Butterfield catfish pond 1; Alabama, Tuscaloosa County, quarry pond; Kentucky, Warren County, spring; Mississippi, Lauderdale County, Kewanee Road, Beaver Pond.

OCCURRENCE. Common in southeastern United States (Dillard 2000).

Euglena satelles Braslavskaja-Spektorova 1937

Fig. $28 \mathrm{a}-\mathrm{c}$

Cells $150-171 \mu \mathrm{m}$ long and 15-16 $\mu \mathrm{m}$ wide, cylindrical, anterior and posterior ends rounded. Euglenoid movement slow and creeping, resulting in substantial change of cell shape. Nucleus in center of cell; chloroplasts parietal, without pyrenoids; paramylon bodies in the form of numerous small oval grains.

SITES: Kentucky, Warren County, spring.

Note. The specimens are similar to Euglena deses representatives. The difference is in the posterior end, which is rounded in E. satelles. Euglena deses specimens have a short, narrow projection.

\section{Euglena vermicularis Proškina-Lavrenko 1937}

Fig. 27

Cell $90 \mu \mathrm{m}$ long and $10 \mu \mathrm{m}$ wide, elongated and cylindrical with narrowing ends, posterior end attached to bottom substrate. Nucleus in center of cell; chloroplasts large, parietal, with rough edges; paramylon grains numerous, small and ovate.

SITES: North Carolina, Macon County, Shopes Farm, upper pond.
Euglena vagans Deflandre 1929 Fig. $29 \& 102$

Cells $63-71 \mu \mathrm{m}$ long and $10 \mu \mathrm{m}$ wide, cylindrical to short cylindrical with small V-shaped cauda. Nucleus in center, two large rod-shaped paramylon grains at both sides of nucleus; chloroplasts small, plate-shaped.

SITES: Kentucky, Warren County, spring.

NoTE. The specimens are longer and wider than given by Deflandre (1929).

Euglena mutabilis F. Schmitz 1884

Figs $30 a, b$ \& 78

Cells 57-65 $\mu \mathrm{m}$ long and 10-11 $\mu \mathrm{m}$ wide, cylindrical with narrowed ends; cells may be attached to substrate at posterior end. Cells bend while swimming. Chloroplasts large, 4-5, thin, flat, closely pressed to wall with pyrenoids.

Sites: Alabama, Sumter County, W. Suffolk pond; Alabama, Tuscaloosa County, quarry pond; Georgia, Sky Valley, Tahoe Road, lake; Tennessee, Blount County, Great Smoky Mountains National Park, stream.

OCCURRENCE. Common in southeastern United States (Dillard 2000).

Euglenaria Karnkowska \& E. W. Linton 2010

Euglenaria anabaena (Mainx) Karnkowska \& E. W. Linton 2010

Fig. 17

Cells 32.5-42.0 $\mu \mathrm{m}$ long and 10-11 $\mu \mathrm{m}$ wide, fusiform, slightly narrowing at posterior end; pellicle spirally striated. A few chloroplasts with double pyrenoids; emergent flagellum as long as cell.

SITES: Kentucky, Warren County, Beechbend Road, farm pond; Kentucky, Warren County, Jackson Orchard, big pond.

\section{Euglenaria caudata var. caudata (Hüber)}

Karnowska \& E. W. Linton 2010

Figs $20,79 \& 103$

Cells 59-77(-137) $\mu \mathrm{m}$ long and 15-26 $\mu \mathrm{m}$ wide, spindle-shaped, elongated, narrowing at anterior end, posterior end with long tail-piece. 

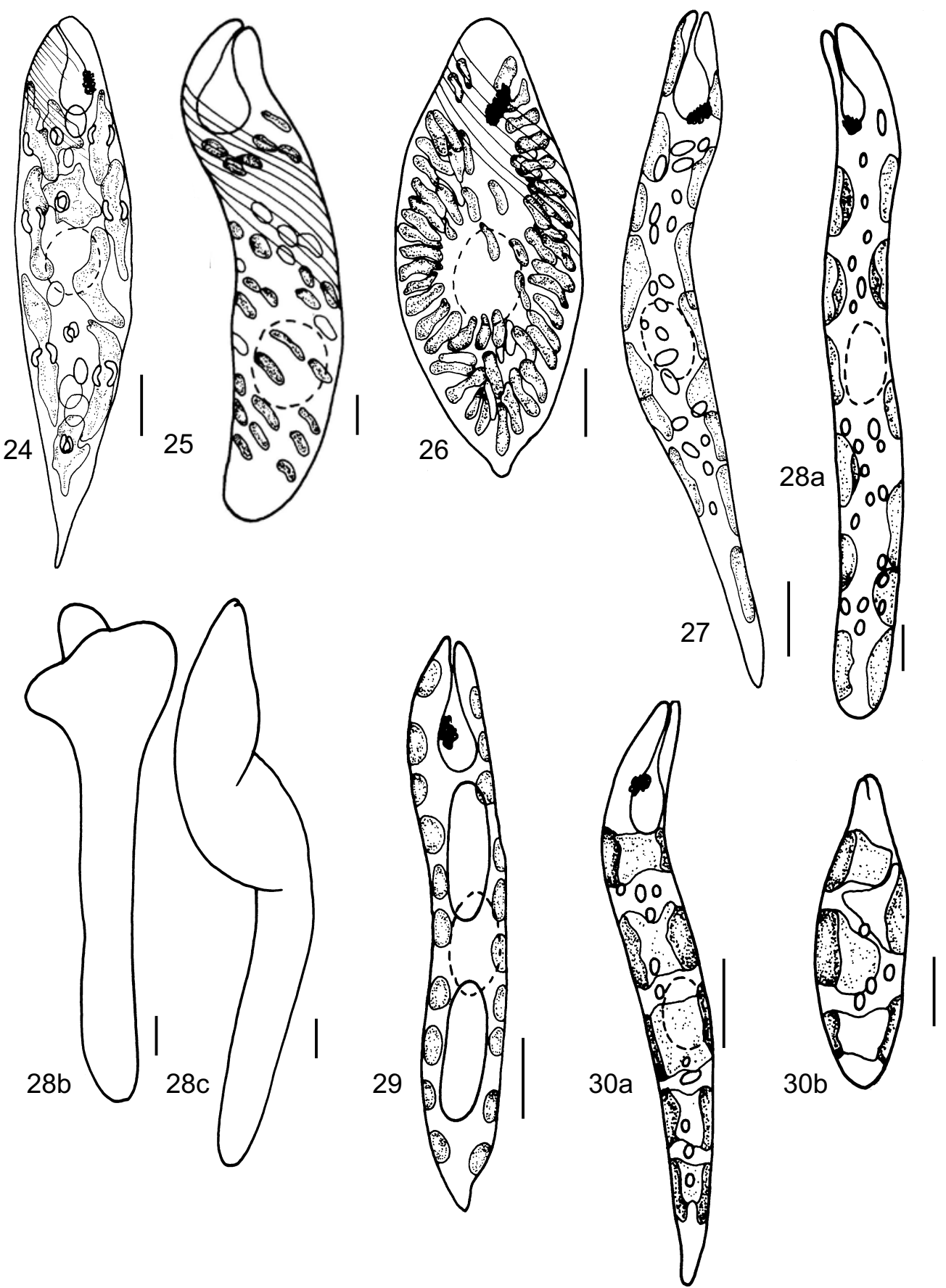

Figs 24-30. 24 - Euglena velata G. A. Klebs, 25 - E. obtusa F. Schmitz, 26 - E. splendens P. A. Dang., $27-$ E. vermicularis Proškina-Lavrenko, 28a, b, c - E. satelles Braslavskaja-Spektorova, b, c - changes of cell shape, 29 - E. vagans Deflandre, 30a, $\mathrm{b}-$ E. mutabilis F. Schmitz. Scale bars $=10 \mu \mathrm{m}$. 
SiTES: Alabama, Sumter County, W. Suffolk pond; Alabama, Tuscaloosa County, small duck pond in University of Alabama area; Alabama, Tuscaloosa County, Butterfield catfish pond (limestone sink); Georgia, Sky Valley, Tahoe Road, lake; Kentucky, Warren County, spring; Mississippi, Lauderdale County, Kewanee Road, ditch; North Carolina, Macon County, Patton and White Roads pond.

OCCURRENCE. As Euglena caudata common in southeastern United States (Dillard 2000).

\section{Lepocinclis Perty 1852}

Lepocinclis ovum (Ehrenb.) Minkiewicz 1898

Figs $31 \& 81$

Chloropeltis ovum F. Stein 1878, Phacus ovum (Ehrenb.) G. A. Klebs 1883, Euglena ovum Ehrenb. 1840, E. zonalis H. J. Carter 1859

Cell $33 \mu \mathrm{m}$ long and $25 \mu \mathrm{m}$ wide, obovoid, ended with short blunt projection; chloroplasts small; two large paramylon bodies.

Sites: Alabama, Tuscaloosa County, small duck pond in University of Alabama area; Tennessee, Knox County, puddle in Cherokee Park.

OCCURRENCE. Very common in southeastern United States (Dillard 2000).

Lepocinclis texta (Dujard.) Lemmerm. var. texta Drezep. 1925 Figs 32, 82 \& 104

Cells 35-45 $\mu \mathrm{m}$ long and 27.5-30.0 $\mu \mathrm{m}$ wide, ovoid, anterior end narrow, posterior end broadly rounded; pellicle spirally striated; small oval paramylon bodies.

Sites: Alabama, Sumter County, W. Suffolk pond; Alabama, Sumter County, Veterans of Foreign Wars, peat bog; Alabama, Sumter County, Livingston University duck pond; Alabama, Sumter County, Butterfield catfish pond (limestone sink); Kentucky, Warren County, Beechbend Road, farm pond; Kentucky, Warren County, Route 240/880, Campgrounds of America pond; Mississippi, Lauderdale County, Kewanee pond; Mississippi, Lauderdale County, Toom Suba Creek;
Mississippi, Lauderdale County, Kewanee pond; Mississippi, Lauderdale County, Kewanee Road, Beaver Pond; North Carolina, Anderson County, Nolan's pond; Tennessee, Knox County, puddle in Cherokee Park; Tennessee, Union County, Brock Road, farm pond near barn.

OCCURRENCE. As Euglena texta common in southeastern United States (Dillard 2000).

Lepocinclis salina fo. obtusa (Hub.-Pest.)

W. Conrad 1934

Fig. 33

Lepocinclis Bütschlii var. obtusa Hub.-Pest. 1929

Cell $45 \mu \mathrm{m}$ long and $25 \mu \mathrm{m}$ wide, ovoid with small projection at posterior end; pellicle spirally striated from right to left; two large and some smaller ring-shaped paramylon grains.

Sites: Alabama, Tuscaloosa County, Butterfield catfish pond 1 .

Lepocinclis cylindrica (Korshikov) W. Conrad 1934

Fig. 34a, b

Lepocinclis ovum var. cylindrica Korshikov 1928

Cell $20 \mu \mathrm{m}$ long and $10 \mu \mathrm{m}$ wide, oval, slightly elongated; pellicle spirally striated from left to right; two large ring-shaped paramylon bodies.

Sites: Mississippi, Lauderdale County, Kewanee Road, ditch.

Lepocinclis steinii Lemmerm. 1901

Fig. 35a, b \& 105

Cell $30 \mu \mathrm{m}$ long and $10 \mu \mathrm{m}$ wide, shortly fusiform with short cauda at posterior end; pellicle longitudinally striated; paramylon grains in the form of clearly visible large rings.

SiTES: Tennessee, Knox County, small basin in Lynnhurst Cemetery.

\section{Lepocinclis marssonii Lemmerm. 1904}

Figs 36a, b, $83 \& 106$

Cells 30-35 $\mu \mathrm{m}$ long and 10.0-10.5 $\mu \mathrm{m}$ wide, elongated, ended with small projection, anterior end truncated; pellicle finely longitudinally stri- 
ated; two ring-shaped paramylon bodies in parietal location.

SITES: Kentucky, Warren County, spring.

OCCURRENCE. Earlier reported from Alabama by Zakryś and Walne (1994).

\section{Lepocinclis acus (O. F. Müller) B. Marin} \& Melkonian 2003

Figs $37 \& 87$

Cells 180-270 $\mu \mathrm{m}$ long and 10-15 $\mu \mathrm{m}$ wide, thin, needle-shaped or tightly spindle-shaped, truncate at anterior end, ended with sharp hyaline cauda; numerous and small discoid chloroplasts; paramylon bodies in the form of several thin rods.

SiTES: Alabama, Sumter County, W. Suffolk pond, Alabama, Tuscaloosa County, Butterfield catfish pond 22; Mississippi, Lauderdale County, Cobb's pond.

Lepocinclis spirogyroides B. Marin \& Melkonian 2003

Figs $38 \& 86$

Euglena spirogyra Ehrenb. 1830

Cells (95-)130-135 $\mu \mathrm{m}$ long and (10.0-)22.0$22.5 \mu \mathrm{m}$ wide, elongated to longitudinally cylindrical with sharp hyaline cauda at posterior end; anterior end rounded; pellicle spirally striated and spirally verrucose.

SITES: Alabama, Sumter County, Nixon's pond; Alabama, Sumter County, Livingston University duck pond; Alabama, Tuscaloosa County, small duck pond in University of Alabama area; Alabama, Tuscaloosa County, Butterfield catfish pond (limestone sink); Alabama, Tuscaloosa County, Butterfield catfish pond 22; Alabama, Tuscaloosa County, Forest Lake Drive; Mississippi, Lauderdale County, Cobb's pond; Mississippi, Lauderdale County, Toom Suba Creek; Tennessee, Union County, Brock Road, farm pond near barn.

\section{Lepocinclis fusca (G. A. Klebs) Kosmala \& Zakryś} 2005

Fig. 39

Euglena spirogyra var. fusca G. A. Klebs 1883

Cell $150 \mu \mathrm{m}$ long and $23 \mu \mathrm{m}$ wide, cylindrical, gradually tapering and passing to sharp cauda; twist of cell is characteristic of that variety; pellicle spirally striated with warts.

SiTES: Alabama, Sumter County, W. Suffolk pond.

Lepocinclis oxyuris (Schmarda) B. Marin

\& Melkonian 2003

Figs $40 \& 84$

Euglena oxyuris Schmarda 1846

Cells 85-155 $\mu \mathrm{m}$ long and 12.5-20.0 $\mu \mathrm{m}$ wide, cylindrical with anterior end rounded and posterior end with long $(37.5 \mu \mathrm{m})$ hyaline cauda.

SITES: Alabama, Sumter County, Nixon's pond; North Carolina, Macon County, Patton and White Roads pond; Mississippi, Lauderdale County, Kewanee Road, Beaver Pond.

Lepocinclis oxyuris var. maior T. G. Popova 1955

Fig. 41

Cells $380-480 \mu \mathrm{m}$ long and 40-50 $\mu \mathrm{m}$ wide, similar to basic species but several times larger; some large rod-shaped paramylon grains.

SITES: Kentucky, Warren County, spring; Tennessee, Union County, Brock Road, farm pond near barn

Lepocinclis oxyuris fo. lata (Christjuk) T. G. Popova 1955

Fig. 42

Cell $199 \mu \mathrm{m}$ long and $29 \mu \mathrm{m}$ wide with hyaline cauda $33 \mu \mathrm{m}$ long; cell curved with rounded ends; pellicle longitudinally striated; chloroplasts very numerous, small and discoid; two large ringshaped paramylon bodies.

SiTES: North Carolina, Macon County, Patton and White Roads pond.

Lepocinclis tripteris (Dujard.) B. Marin \& Melkonian 2003

Figs $43 \mathrm{a}-\mathrm{c} \& 85$

Euglena tripteris (Dujard.) G. A. Klebs 1883

Cells 69-80 (426) $\mu \mathrm{m}$ long and 9-15 (35) $\mu \mathrm{m}$ wide, cells elongated, triangular, slightly twisted with anterior end rounded, posterior end has sharp 
hyaline cauda; pellicle finely striated longitudinally; two long rod- or ring-shaped paramylon grains. Flagellum shorter than cell.

SITES: Alabama, Sumter County, Nixon's pond; Alabama, Tuscaloosa County, Butterfield catfish pond (limestone sink); Alabama, Tuscaloosa County, Butterfield catfish pond 22; Kentucky, Warren County, spring; North Carolina, Anderson County, roadside pond.

Phacus Dujard. 1841

Phacus parvulus G. A. Klebs 1883

Figs $44 \& 88$

Cell $20 \mu \mathrm{m}$ long and $11 \mu \mathrm{m}$ wide, oval, ended by small blunt process; periplast very gently striated obliquely; one large circular paramylon grain in central part of cell.

SiTES: Tennessee, Knox County, small basin in Lynnhurst Cemetery.

Phacus pusillus Lemmerm. 1910

Figs $45 \& 89$

Cell $24 \mu \mathrm{m}$ long and $11 \mu \mathrm{m}$ wide, oval or eggshaped in outline with fold running along cell (to $1 / 3$ third or $1 / 2$ cell length); chloroplasts numerous, small and disc-shaped; two ring-like paramylon bodies.

SITES: Tennessee, Knox County, small basin in Lynnhurst Cemetery.

Phacus dangeardii Lemmerm. 1910

Fig. 46a, b

Cell $18.5 \mu \mathrm{m}$ long and $11.0 \mu \mathrm{m}$ wide, oval and flattened with shallow furrow running along cell; one oval, centrally situated paramylon grain.

SITES: Tennessee, Knox County, small basin in Lynnhurst Cemetery.

\section{Phacus fominii Y. V. Roll $1938 \quad$ Fig. 47a, b}

Cell $40 \mu \mathrm{m}$ long and $10 \mu \mathrm{m}$ wide, round with small depression at top; pellicle longitudinally striated; one ring-like paramylon grain.
Sites: Alabama, Sumter County, Nixon's pond.

Phacus acuminatus A. Stokes 1881

Figs 48, $90 \& 107$

Cell $35 \mu \mathrm{m}$ long and $24 \mu \mathrm{m}$ wide with dorsal furrow running to $3 / 4$ of cell length; posterior end with small straight projection; pellicle longitudinally striated; chloroplasts numerous, small, disc-shaped; two paramylon bodies disc-like in outline.

SITES: Alabama, Tuscaloosa County, University of Alabama lake; Tennessee, Knox County, small basin in Lynnhurst Cemetery.

OCCURRENCE. Common in southeastern United States (Dillard 2000).

Phacus oscillans G. A. Klebs 1883

Figs 49a, b \& 91

Cell $22.0 \mu \mathrm{m}$ long and $9.5 \mu \mathrm{m}$ wide, asymmetrical, with two convoluted lobes along cell, in cross section triangular; pellicle spirally striated. Small chloroplasts, two large paramylon bodies.

SITES: Tennessee, Knox County, fish pond.

OCCURRENCE. Earlier reported from Alabama by Ratnasabapathy \& Deason (1977).

Phacus undulatus (Skvortsov) Pochm. 1941

Fig. $50 \& 108$

Phacus pleuronectes var. insecta Koczwara 1916; Ph. anacoelus var. undulata Skvortsov 1922

Cells 47-55 $\mu \mathrm{m}$ long and 30-35 $\mu \mathrm{m}$ wide, broadly oval, flattened, undulated at cell rim, ended by long, sharp, curved cauda; pellicle longitudinally striated; chloroplasts numerous, small; one central ring-shaped paramylon grain.

Sites: Alabama, Tuscaloosa County, University of Alabama lake.

Phacus unguis Pochm. 1941

Figs $51 \& 92$

Cells 35-37 $\mu \mathrm{m}$ long and 17-24 $\mu \mathrm{m}$ wide, obovoid in outline, distinctly undulate at rim, 

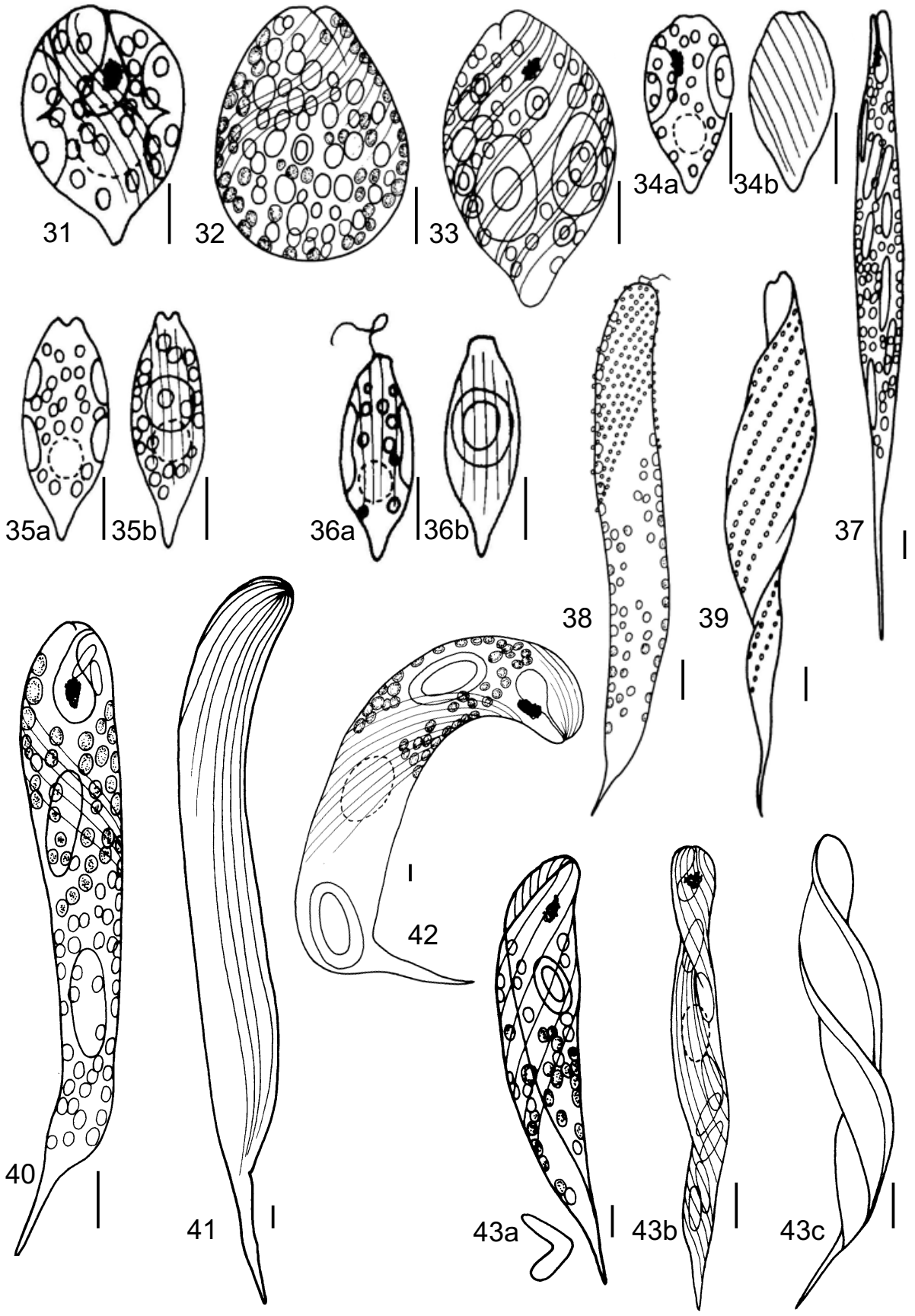

Figs 31-43. 31 - Lepocinclis ovum (Ehrenb.) Minkiewicz, 32 - L. texta var. texta Drezep., 33 - L. salina var. obtusa (Hub.-Pest.) W. Conrad, 34a, b - L. cylindrica (Korshikov) W. Conrad, 35a, b - L. steinii Lemmerm., 36a, b - L. marssonii Lemmerm., 37 - L. acus (O. F. Müller) B. Marin \& Melkonian, 38 - L. spirogyroides B. Marin \& Melkonian, 39 - L. fusca (G. A. Klebs) Kosmala \& Zakryś, 40 - L. oxyuris (Schmarda) B. Marin \& Melkonian, 41 - L. oxyuris var. maior T. G. Popova, 42 - L. oxyuris var. lata (Christjuk) T. G. Popova, 43a, b, c - L. tripteris (Dujard.) B. Marin \& Melkonian. Scale bars $=10 \mu \mathrm{m}$. 
ended by short sharp cauda; pellicle longitudinally striated; chloroplasts small, disc-shaped; paramylon grain ring-shaped in outline.

SITES: Alabama, Sumter County, Nixon's pond; Tennessee, Knox County, small basin in Lynnhurst Cemetery.

Phacus orbicularis K. Hübner 1886

Figs 52a, b, 93 \& 109

Cells 45.0-80.5 $\mu \mathrm{m}$ long and 30-45 $\mu \mathrm{m}$ wide with 8-20 $\mu \mathrm{m}$ long cauda, oval to round in outline; cells usually with 1-2 discoid paramylon grains.

SiTES: Kentucky, Warren County, spring; Mississippi, Lauderdale County, Kewanee Road, ditch; Alabama, Tuscaloosa County, Forest Lake; Alabama, Tuscaloosa County, quarry pond; Mississippi, Lauderdale County, Kewanee Road, ditch; Tennessee, Knox County, small basin in Lynnhurst Cemetery; Tennessee, Union County, Brock Road, farm pond near barn.

OCCURRENCE. Very common in southeastern United States (Dillard 2000).

Phacus pleuronectes (Ehrenb.) Dujard. 1925

Figs 53, 94 \& 110

Euglena pleuronectes Ehrenb. 1838

Cells 37-50 $\mu \mathrm{m}$ long and 29-35 $\mu \mathrm{m}$ wide, broadly oval, flat, slightly narrowed at anterior end, posterior end with short curved cauda.

SITES: Alabama, Sumter County, Nixon's pond; Alabama, Tuscaloosa County, Forest Lake Drive; Mississippi, Lauderdale County, Kewanee Road, Beaver Pond; Mississippi, Lauderdale County, Kewanee Road, ditch; Tennessee, Union County, Malueg Farm, upper pond; Tennessee, Knox County, puddle in Cherokee Park; Tennessee, Union County, Malueg Farm, upper pond.

OCCURRENCE. Very common in southeastern United States (Dillard 2000).

Phacus ankylonoton Pochm. 1941 Fig. 54a, b

Cell $41 \mu \mathrm{m}$ long and $20 \mu \mathrm{m}$ wide, oval to slightly elongated with straight, hyaline cauda at posterior end; pellicle longitudinally striated; one ring-shaped paramylon body.

SiTES: Tennessee, Union County, Malueg Farm, small pond on right side.

Phacus hamelii P. Allorge \& M. Lefèvre 1931

Fig. $55 \mathrm{a}, \mathrm{b}$

Cells 32.3-35.0 $\mu \mathrm{m}$ long and 17.0-17.5 $\mu \mathrm{m}$ wide, oval or tightly oval, ended by straight, sharp cauda with keel running along cell length; one disc-shaped paramylon grain.

SiTES: Mississippi, Lauderdale County, Kewanee Road, ditch.

Phacus triqueter (Ehrenb.) Dujard. 1841

Figs 56a-c, $96 \& 111$

Cells 40-50 $\mu \mathrm{m}$ long and 25-35 $\mu \mathrm{m}$ wide, oval with characteristic wide keel running along cell; cells triangular in cross section; one large paramylon grain in centrally location.

SITES: Alabama, Sumter County, small duck pond in University of Alabama area; Alabama, Tuscaloosa County, Forest Lake; Kentucky, Warren County, Slim Is., Jackson Orchard small pond; Tennessee, Union County, Malueg Farm, upper pond; Tennessee, Knox County, small basin in Lynnhurst Cemetery; Tennessee, Union County, Malueg Farm, upper pond.

OCCURRENCE. Very common in southeastern United States (Dillard 2000).

Phacus alatus G. A. Klebs 1883 Fig. 57a, b

Cell $32.5 \mu \mathrm{m}$ long and $23.0 \mu \mathrm{m}$ wide, asymmetrical with sharp curved cauda; two large round paramylon bodies.

Sites: Mississippi, Lauderdale County, Kewanee Road, Beaver Pond.

OCCURRENCE. Earlier reported from Tennessee by Bevel (1938), Georgia by Patrick et al. (1967) and Kentucky by Taylor et al. (1977). 

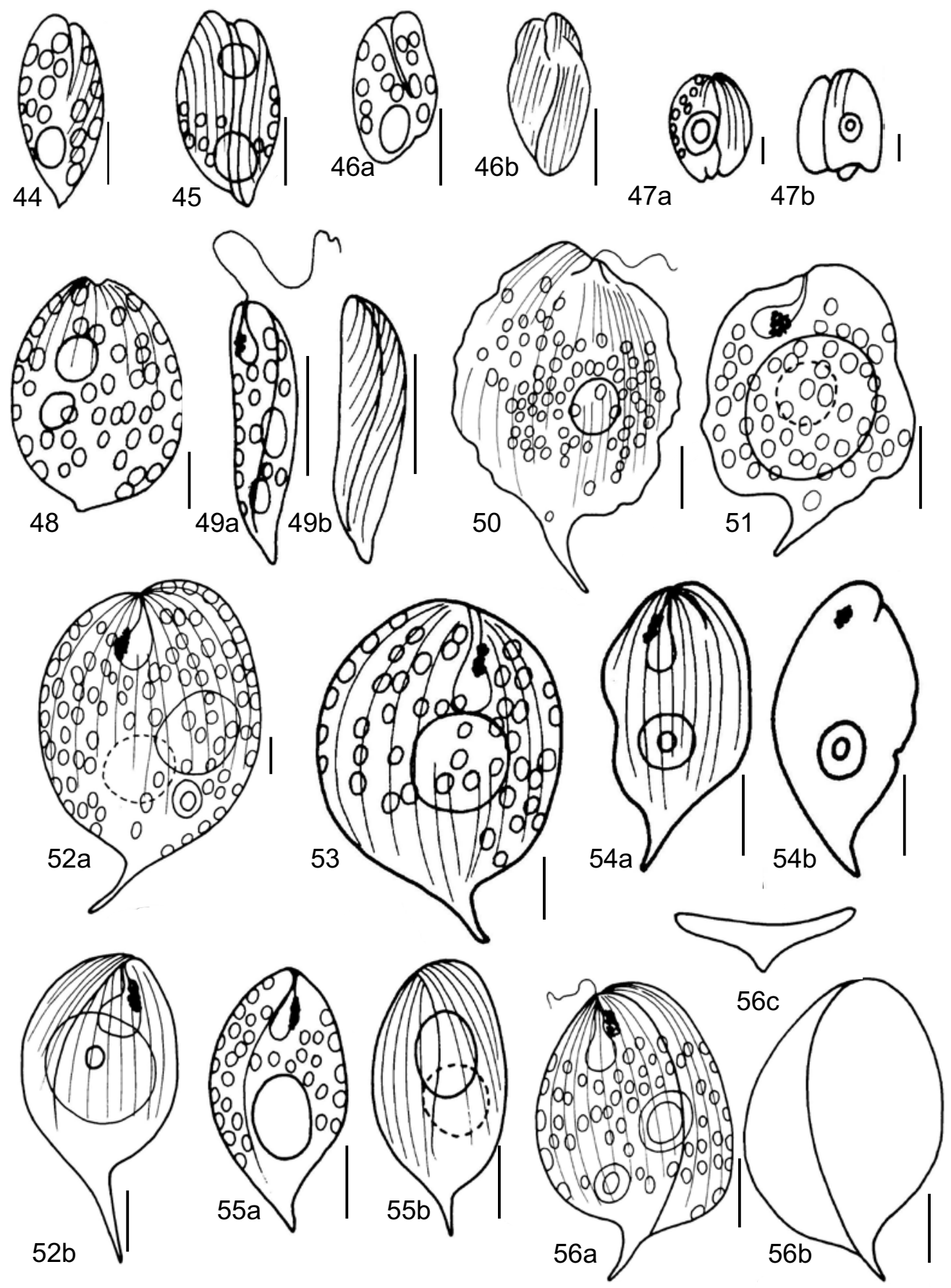

Figs 44-56. 44 - Phacus parvulus G. A. Klebs, 45 - Ph. pusillus Lemmerm., 46a, b - Ph. dangeardii Lemmerm., 47a, b - Ph. fominii Y. V. Roll, 48 - Ph. acuminatus A. Stokes, 49a, b - Ph. oscillans G. A. Klebs, 50 - Ph. undulatus (Skvortsov) Pochm., 51 - Ph. unguis Pochm., 52a, b - Ph. orbicularis K.Hübner, 53 - Ph. pleuronectes (Ehrenb.) Dujard., 54a, b - Ph. ankylonoton Pochm., 55a, b - Ph. hamelii P. Allorge \& M. Lefèvre, 56a, b, c - Ph. triqueter (Ehrenb.) Dujard. Scale bars $=10 \mu \mathrm{m}$. 
Phacus curvicauda Svirenko 1915

Figs 58a, b, $97 \& 112$

Cells (21-)39-41 $\mu \mathrm{m}$ long and (18.0-)29.0$32.5 \mu \mathrm{m}$ wide, oval to round, slightly asymmetrical, ended with bent hyaline cauda; two large paramylon bodies.

SITES: Kentucky, Warren County, Beechbend Road, farm pond; Mississippi, Lauderdale County, Kewanee Road, Beaver Pond; Tennessee, Knox County, small basin in Lynnhurst Cemetery.

OCCURRENCE. Earlier reported from Georgia by Morris et al. (1977) and Mississippi by Williams et al. (1977).

Phacus raciborskii Drezep. 1925

Figs 59a, b \& 95

Cells 35.0-37.5 $\mu \mathrm{m}$ long and 10.0-12.2 $\mu \mathrm{m}$ wide with cauda $c a 10 \mu \mathrm{m}$ long; cells irregular in outline, slightly twisted and bent, ended by sharp cauda; pellicle longitudinally striated; chloroplasts small, disc-shaped, one ring-like paramylon body.

Sites: Alabama, Sumter County, Nixon's pond.

Phacus longicauda (Ehrenb.) Dujard. 1841

Fig. 60

Euglena longicauda Ehrenb. 1838

Cells 65-166 $\mu \mathrm{m}$ long and 33-60 $\mu \mathrm{m}$ wide, oval to broadly oval, flattened with long straight cauda $(25.0-68.5 \mu \mathrm{m})$ on posterior end; numerous small chloroplasts; single large paramylon grain in center, accompanied by $2-3$ smaller ones.

SiTES: Alabama, Sumter County, duck pond; Alabama, Tuscaloosa County, Butterfield catfish pond 1; Alabama, Tuscaloosa County, Forest Lake; Mississippi, Lauderdale County, Toom Suba Creek; Mississippi, Lauderdale County, Kewanee Road, Beaver Pond; North Carolina, Macon County, Shopes Farm, upper pond; Tennessee, Knox County, puddle in Cherokee Park.
OCCURRENCE. Very common in southeastern United States (Dillard 2000).

Phacus longicauda var. attenuata (Pochm.) Hub.Pest. 1955

Fig. 61

Phacus longicauda subsp. attenuata Pochm. 1842

Cell $170 \mu \mathrm{m}$ long and $65 \mu \mathrm{m}$ wide with long and clearly curved cauda.

Sites: Alabama, Tuscaloosa County, Butterfield catfish pond 1 .

Phacus longicauda var. rotunda (Pochm.) Hub.Pest. 1955

Fig. 62

Phacus longicauda subsp. rotunda Pochm. 1842

Cell $105 \mu \mathrm{m}$ long and $32.5 \mu \mathrm{m}$ wide with cauda $50 \mu \mathrm{m}$ long; cell slightly asymmetrical.

SiTeS: Alabama, Tuscaloosa County, Butterfield catfish pond 1 .

Phacus circumflexus Pochm. 1941

Fig. $63 \& 113$

Cell $75 \mu \mathrm{m}$ long and $38 \mu \mathrm{m}$ wide, round with folded rim in upper part of cell; posterior end with long thick cauda; striation slightly oblique; some large disc-shaped paramylon bodies grouped in central part of cell.

Sites: Alabama, Tuscaloosa County, Butterfield catfish pond 1 .

Note. This taxon closely resembles Phacus longicauda (Ehrenb.) Dujard. 1841. Popova and Safonova (1976) classified it as Ph. longicauda var. tortus but according to Pochmann (1941) it should be separated as a species in view of its dissimilarity in the structure of the upper part of the cell.

Phacus ephippion Pochm. 1941 Figs 64 \& 98

Cells $70-75 \mu \mathrm{m}$ long (incl. $35 \mu \mathrm{m}$ process) and 30-35 $\mu \mathrm{m}$ wide; cells round, ended by long, straight, sharp cauda; cell rim rugose and irregular in outline; chloroplasts small, numerous, 

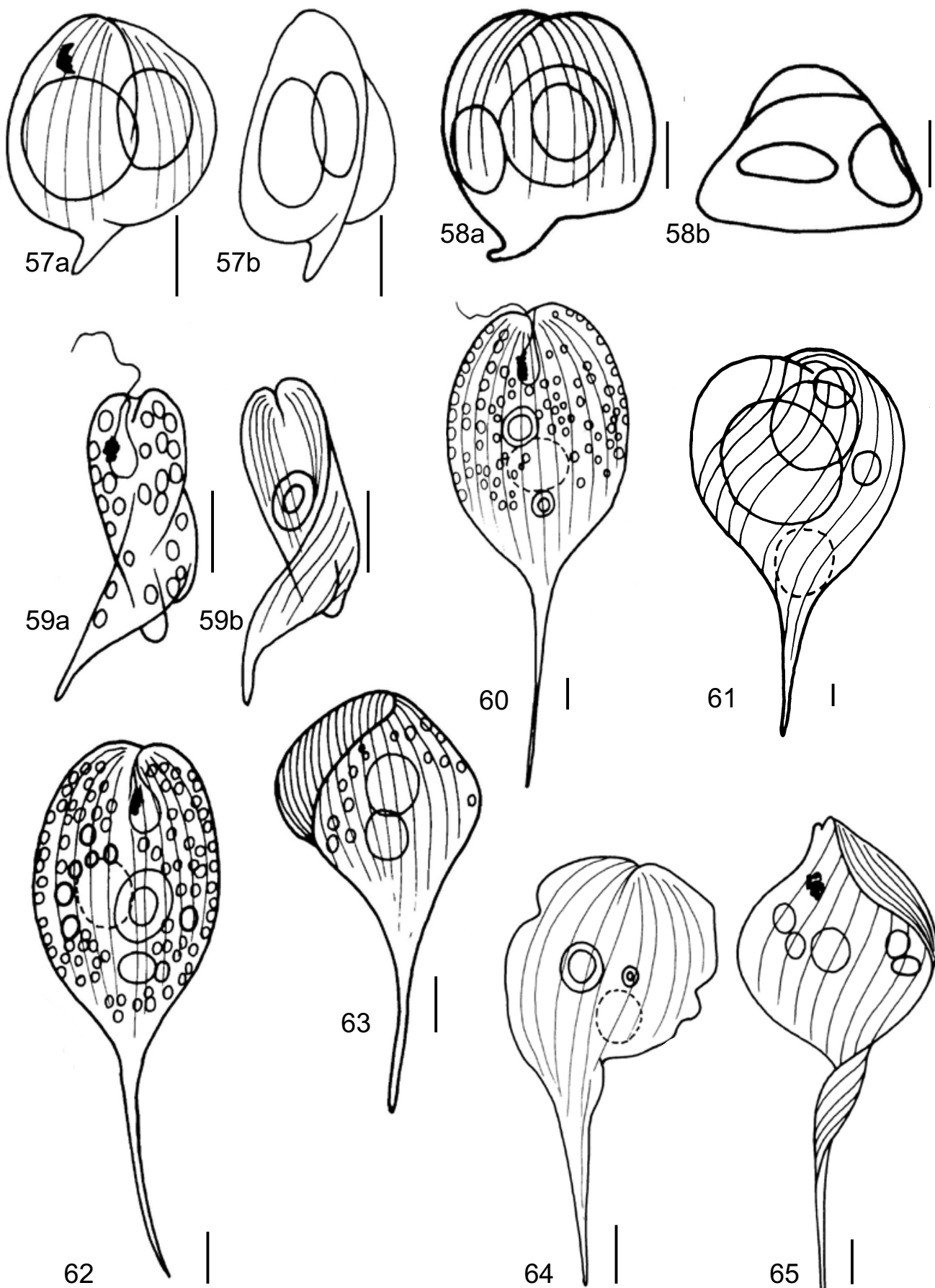
disc-shaped; one ring-shaped centrally located paramylon grain.

SiTES: Kentucky, Warren County, Jackson Orchard, big pond.

Note. The species resembles Phacus longicauda (Ehrenb.) Dujard. 1841. Popova and Safonova (1976) included it in Ph. longicauda var. tortus. We classified our specimen in Ph. ephippion according to Pochmann (1941).

Phacus helikoides Pochm. 1941

Figs $65,99 \& 114$

Cells 105-116 $\mu \mathrm{m}$ long and 32-49 $\mu \mathrm{m}$ wide, 50-59 $\mu \mathrm{m}$ long, straight, sharp cauda at posterior end; cells twisted twice; some large paramylon bodies in central part.

Sites: Mississippi, Lauderdale County, Kewanee Road, Beaver Pond.

OCCURRENCE. Earlier reported from North Carolina by Schumacher and Whitford (1961), Kentucky by Dillard (1967) and Georgia by Morris et al. (1977).

Note. According to Popova and Safonova (1976) it should be classified as Ph. longicauda var. tortus fo. helikoides. According to Pochmann (1941) it is a separate species in view of differences in the upper part of the cell.

\section{Phacus smulkowskianus (Zakryś) Kusber 1998}

Figs 66a, b \& 100

Euglena smulkowskiana Zakryś 1986, Phacus similis Christen 1962, Ph. similis fo. minor Bourrelly \& Coute 1978

Cell $35 \mu \mathrm{m}$ long and $15 \mu \mathrm{m}$ wide, twisted three times and ended by straight cauda; pellicle stripes helically arranged in accordance with the twist of the cell; chloroplasts rather small, numerous; two large discoid paramylon grains.

SiTES: Tennessee, Knox County, small basin in Lynnhurst Cemetery.

Note. The species is very similar to $P h$. helikoides but the cells are smaller and the cauda is shorter. In our opinion the type of cell structure differs.

Phacus monilatus (A. Stokes) Lemmerm. 1901 Figs $67 \mathrm{a}, \mathrm{b} \& 101$

Chloropeltis monilata A. Stokes 1830

Cells 32.5-35.0 $\mu \mathrm{m}$ long and 20-21 $\mu \mathrm{m}$ wide, broadly oval to round with straight, short, thick process; pellicle densely covered with rows of warts; apical part with small papilla; chloroplasts numerous, small, discoid; paramylon in the form of two ring-shaped grains.

Sites: Alabama, Sumter County, W. Suffolk pond; North Carolina, Macon County, Shopes Farm, upper pond.

\section{Phacus sp.}

Fig. $68 \mathrm{a}-\mathrm{c}$

Cells 36.0-37.5 $\mu \mathrm{m}$ long and 12.0-12.5 $\mu \mathrm{m}$ wide, fusiform to triangular, twisted, star-shaped in cross section; apical part rounded, narrowing towards posterior end with cauda 10-11 $\mu \mathrm{m}$ long; pellicle longitudinally striated; chloroplasts numerous, small, plate-shaped; flagellum short - 1/4 of cell length or shorter.

Sites: Alabama, Sumter County, Nixon's pond.

Note. The species is similar to $P$ h. raciborskii but our taxon is more regular in outline. It is also similar to Ph. trimarginatus but this one is larger and has three ribs passing along the cell.

Monomorphina Mereschkovski 1887

Monomorphina pyrum (Ehrenb.) Mereschkovski 1887

Fig. 69a, b \& 115

Euglena pyrum Ehrenberg 1832

Cells 32.5-33.0 $\mu \mathrm{m}$ long and 12.0-12.5 $\mu \mathrm{m}$ wide, pear-shaped and ended by straight cauda; pellicle spirally ribbed; small chloroplasts; two large bowl-shaped lateral paramylon grains. pond.

Sites: Alabama, Sumter County, Nixon's 

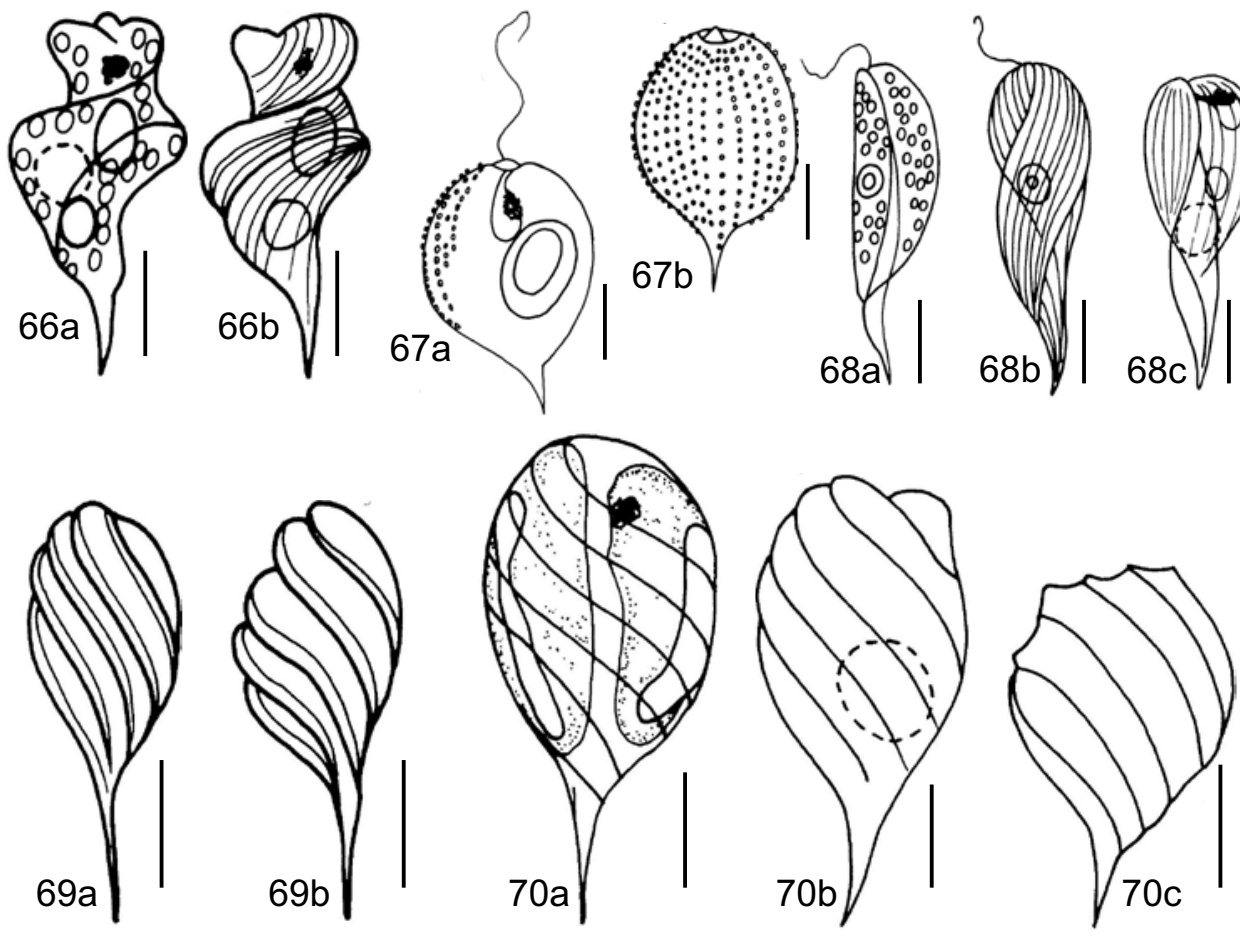

Figs 66-70. 66a, b - Phacus smulkowskianus (Zakryś) Kusber, 67a, b - Ph. monilatus (A. Stokes) Lemmerm., 68a, b, c-Ph. sp., 69a, b-Monomorphina pyrum (Ehrenb.) Mereschkovski, 70a, b, c - M. splendens (Pochm.) T. G. Popova. Scale bars $=10 \mu \mathrm{m}$

Monomorphina splendens (Pochm.) T. G. Popova 1947

Fig. 70a-c

Phacus splendens Pochm. 1942

Cells 30-40 $\mu \mathrm{m}$ long and 16-18 $\mu \mathrm{m}$ wide, process $12-15 \mu \mathrm{m}$ long, pear-shaped with straight cauda on posterior end, anterior end widely rounded; pellicle spirally ribbed; two large laterally situated chloroplasts, each accompanied by a large paramylon grain.

SITES: Alabama, Sumter County, duck pond; Kentucky, Warren County, Beechbend Road, farm pond; Kentucky, Warren County, spring.

\section{ECOLOGICAL ASPECTS}

Physicochemical conditions varied in the studied habitats with euglenoids, especially with reference to water $\mathrm{pH}$ and temperature. They can be characterized as neutral to strongly alkaline; only a few had $\mathrm{pH}<7$. Water temperature ranged from 10 to even $35^{\circ} \mathrm{C}$, but the majority of the sites had water temperature above $20^{\circ} \mathrm{C}$. A parameter that undoubtedly had an influence on the euglenoid community was specific conductance. The ion concentrations were moderate, usually $0.1-$ $0.2 \mathrm{mS} \mathrm{cm}^{-1}$ but in some cases above $2.0 \mathrm{mS} \mathrm{cm}^{-1}$ (Table 1). The majority of the identified taxa were found in the littoral zone of the water bodies. The sites were associated with bottom habitat; the euglenoids developed in/on mud or green mud accumulated at the bottom, though quite a number of species also occurred in plankton (Table 2). In general, no taxa were closely connected with any zone of freshwater. Usually the same taxa were noted in different types of habitat. The richness of taxa was greatest in water bodies of Alabama (35) and Tennessee (25) and least in Georgia (5), but it should be stressed that in Georgia the fewest sites were studied. 

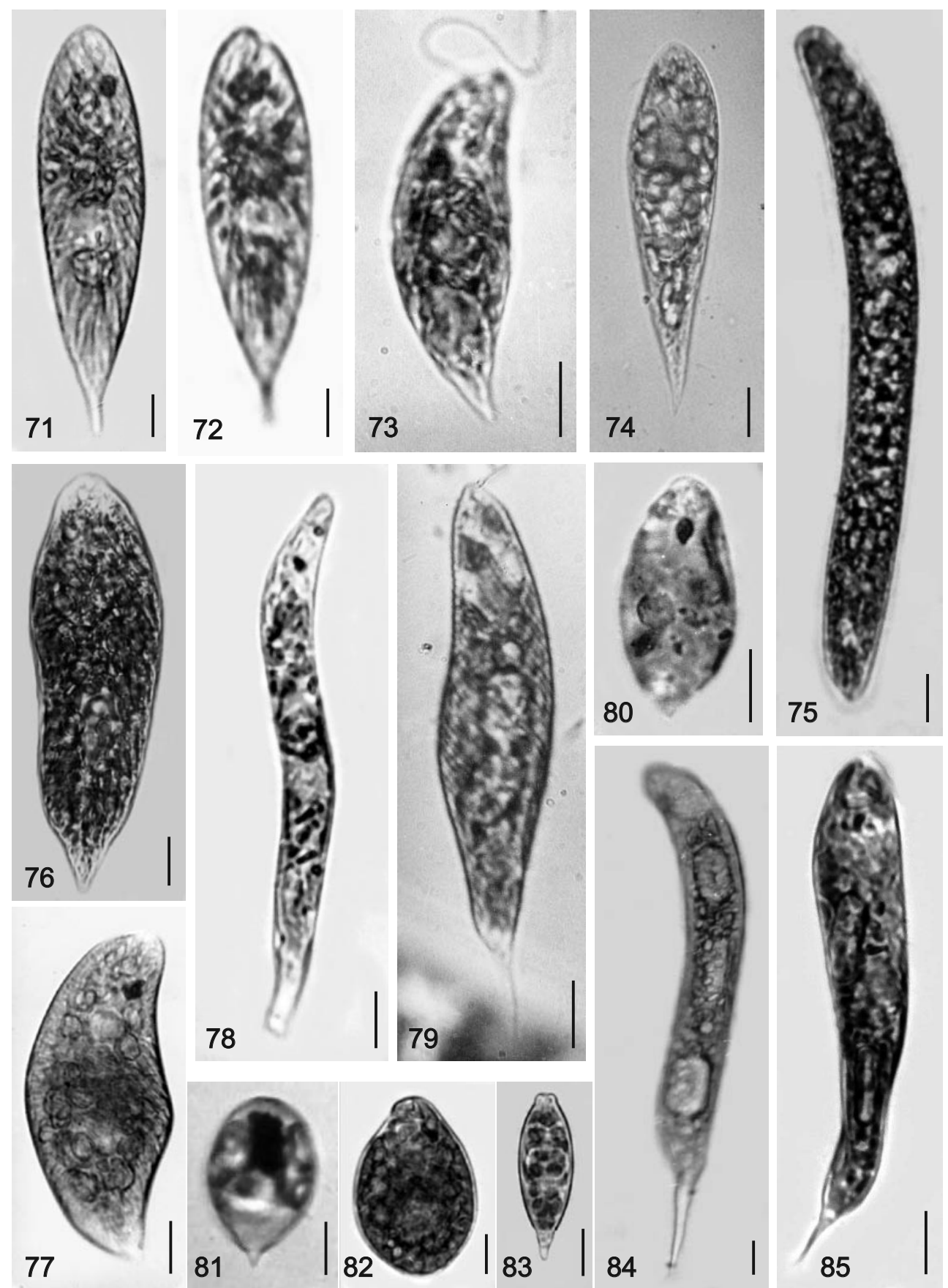

Figs 71-85. 71 - Euglena geniculata Dujard., $72-$ E. tristella S. P. Chu, $73-$ E. viridis Ehrenb., $74-$ E. hemichromata Skuja, $75-$ E. ehrenbergii G. A. Klebs, $76-$ E. sociabilis P. A. Dang., 77 - E. splendens P. A. Dang., 78 - E. mutabilis F. Schmitz, 79 - Euglenaria caudata var. caudata (Hüber) Karnowska \& E. W. Linton, 80 - Euglena agilis H. J. Carter, 81 - Lepocinclis ovum (Ehrenb.) Minkiewicz, 82 - L. texta var. texta Drezep., 83 - L. marssonii Lemmerm., $84-$ L. oxyuris (Schmarda) B. Marin $\&$ Melkonian, $85-$ L. tripteris (Dujard.) B. Marin \& Melkonian. Scale bars $=10 \mu \mathrm{m}$. 


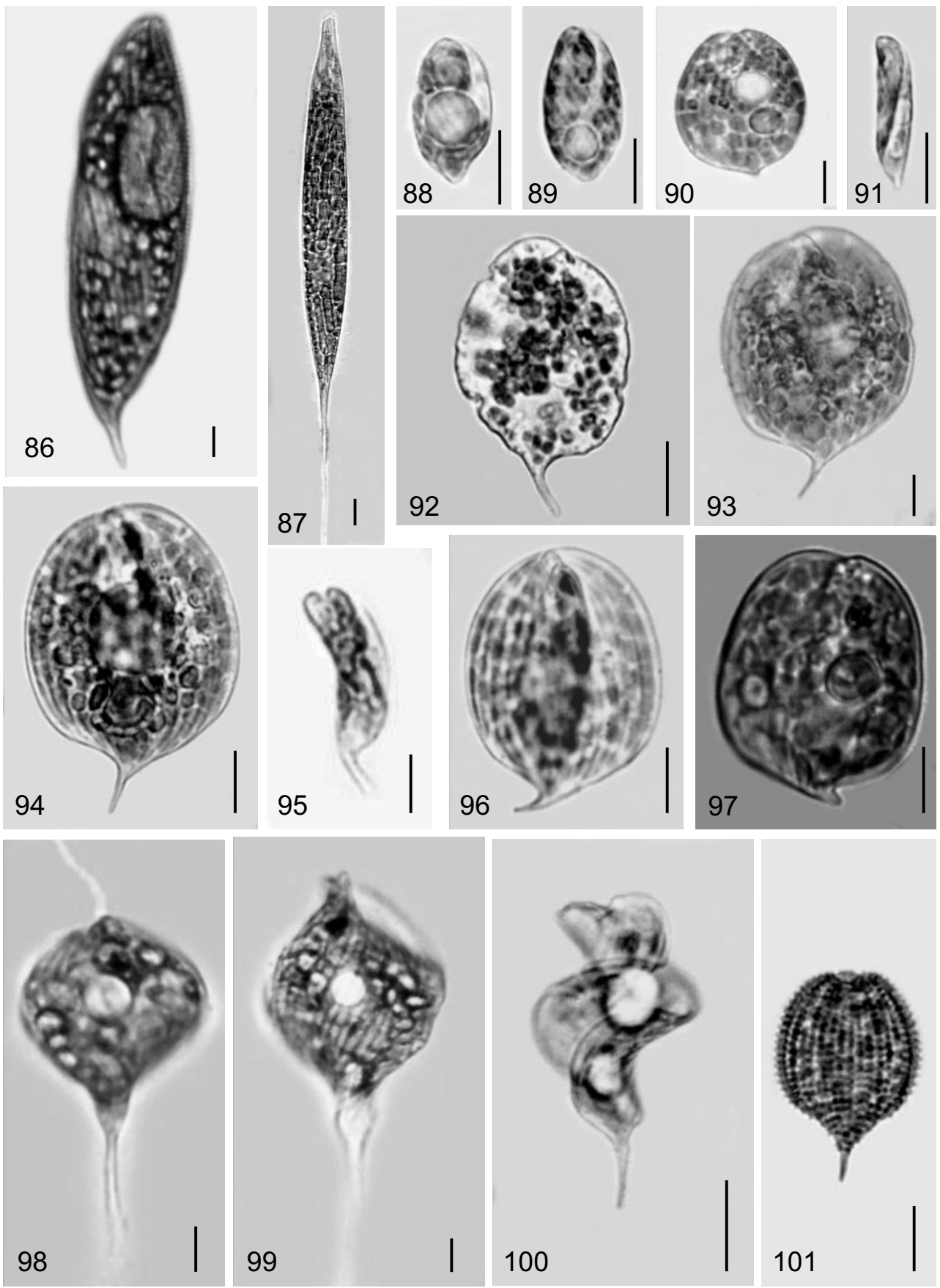

Figs 86-101. 86 - Lepocinclis spirogyroides B. Marin \& Melkonian, 87 - L. acus (O. F. Müller) B. Marin \& Melkonian, 88 - Phacus parvulus G. A. Klebs, 89 - Ph. pusillus Lemmerm., 90 - Ph. acuminatus A. Stokes, 91 - Ph. oscillans G. A. Klebs, 92 - Ph. unguis Pochm., 93 - Ph. orbicularis K. Hübner, 94 - Ph. pleuronectes (Ehrenb.) Dujard., 95 - Ph. raciborskii Drezep., 96 - Ph. triqueter (Ehrenb.) Dujard., 97 - Ph. curvicauda Svirenko, 98 - Ph. ephippion Pochm., 99 - Ph. helikoides Pochm., $100-$ Ph. smulkowskianus (Zakryś) Kusber, $101-P h$. monilatus (A. Stokes) Lemmerm. Scale bars $=10 \mu \mathrm{m}$. 


\section{DISCUSSION}

The 68 taxa represent two groups, one with a flexible periplast (Euglena and Euglenaria) and the other with a rather rigid periplast (Phacus and Monomorphina); 28 taxa of the former type were identified, and 40 of the latter. Most are cosmopolitan, though their distribution is best documented from Europe (e.g., Wołowski 1989, 1998, 2003; Kusel-Fetzmann 2002) and South America (e.g., Tell \& Conforti 1986; Conforti \& Perez 2000). Some species have been noted frequently in the United States as well: for example, Euglena viridis, E. proxima, E. ehrenbergii, E. agilis, E. polymorpha, E. sociabilis, E. splendens and E. mutabilis. Within Phacus there were also species common in the southeastern United States: $P h$. acuminatus, $P h$. orbicularis, $P h$. pleuronectes, $P h$. triqueter and Ph. longicauda. Within Lepocinclis there were only two taxa considered common in the southeastern United States: Lepocinclis ovum var. ovum and L. texta (previously known as Euglena texta). In this study the most frequently noted taxa were Euglenaria caudata var. caudata, Lepocinclis texta var. texta, Phacus pleuronectes and Ph. orbicularis. Many of the others either are new for the region or their presence in southeastern American water bodies was based on old data, mainly Patrick et al. (1967), Morris et al. (1977), Williams et al. (1977) or even older.

The species determined in this study and apparently rare elsewhere in the world were Euglena cuneata, E. tuberculata, Phacus fominii and Ph. ephippion. The first was found in a peat bog in Alabama, the rest in ponds where they were collected from the surface of bottom mud or from squeezed plants. Euglena cuneata is known from the UK (Wołowski 2011) and recently it was recorded from the River Bahuda in eastern India (Bhakta et al. 2011). Euglena tuberculata was recorded from a lake in Turkey (Ersanli \& Gönülol 2006) and
Romania (Cărăus 2012). Until now Phacus fominii has been reported from only a few natural habitats in eastern and western Ukraine (Vetrova 2004). Phacus ephippion has been recorded from various locations, for example a pond in Bangladesh (Khondker et al. 2008) and some other tropical sites, but lacking illustrations to support identification. There is a record by Ratha et al. (2006) from a pond in eastern India, where a bloom occurred. However, the picture (Plate 3, Fig. 11) displays $P h$. tortus so it probably is misidentified.

Some cosmopolitan widespread taxa such as Euglena geniculata, Phacus pusillus and Ph.parvulus have only one or two records or even none from the southeastern United States. This most likely is due to insufficient study of the euglenoid flora of this part of the United States

The majority of the taxa were associated with warm water with relatively high $\mathrm{pH}$. Although they have a wide ecological spectrum with respect to physical and chemical properties they seem to be typical in such types of water. Many papers have documented the abundant development of euglenoids in countries with a warm climate (Heckmann et al. 1996; Conforti \& Perez 2000; Wołowski \& Walne 2007; Yamagishi 2010; Duangjan et al. 2012; Duangjan \& Wołowski 2013); in the temperate zone they usually occur in summer or a warm autumn (Cabała 2003; Poniewozik 2009). There is a relative lack of studies on the environmental requirements of particular euglenophyte taxa.

ACKNOWLEDGEMENTS. We thank Professor Brian A. Whitton for helping with the English version of the manuscript, and Professor František Hindák and the anonymous reviewer for very helpful remarks. This research received support from L. R. Hesler Visiting Professorship from the Department of Botany, University of Tennessee, Knoxville, from the Polish Committee of Scientific Research (grant P04C 03621), and from the W. Szafer Institute of Botany of the Polish Academy of Sciences through its statutory funds.

Figs 102-115. 102 - Euglena vagans Deflandre, 103 - Euglenaria caudata var. caudata (Hüber) Karnowska \& E. W. Linton, 104 - Lepocinclis texta var. texta Drezep., 105 - L. steinii Lemmerm., 106 - L. marssonii Lemmerm., 107 - Phacus acuminatus A. Stokes, 108 - Ph. undulatus (Skvortsov) Pochm., 109 - Ph. orbicularis K. Hübner, 110 - Ph. pleuronectes (Ehrenb.) Dujard., 111 - Ph. triqueter (Ehrenb.) Dujard., 112 - Ph. curvicauda Svirenko, 113 - Ph. circumflexus Pochm., $114-$ Ph. helikoides Pochm., 115 - Monomorphina pyrum (Ehrenb.) Mereschkovski. Scale bars $=10 \mu \mathrm{m}$. 

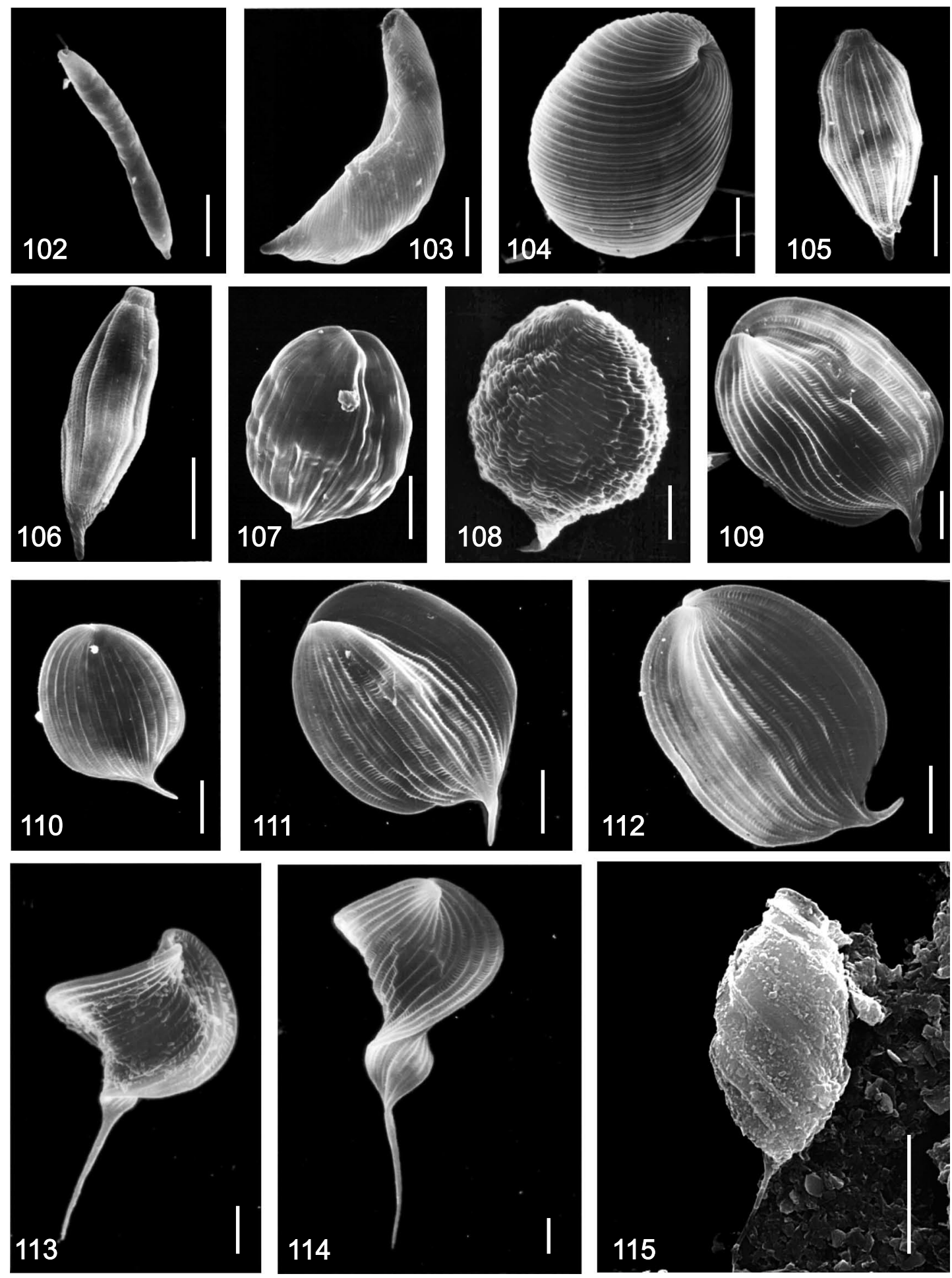


\section{REFERENCES}

BEVEL N. 1938. Some notes on the protozoa of Reelfoot Lake. J. Tennessee Acad. Sci. 13: 137-149.

Bhakta S., Das S. K., Nayak M., Jena J., Panda P. K. \& SuKLA L. B. 2011. Phyco-diversity assessment of Bahuda River mouth areas of east coast of Odisha, India. Recent Research in Science and Technology 2(4):80-89.

Bovee E. 1960. Protozoa of the Mountain Lake region, Giles County, Virginia. J. Protozool. 7: 352-361.

Brosnan S., Brown P. J., FARmer M. A. \& Triemer R. E. 2005. Morphological separation of the euglenoid genera Trachelomonas and Strombomonas (Euglenophyta) based on lorica development and posterior strip reduction. J. Phycol. 41: 590-605.

CABAŁA J. 2003. Some interesting colourless euglenophytes found in southern Poland. Acta Soc. Bot. Poloniae 72(3): 243-247.

CĂRĂUS I. 2012. Algae of Romania. A distributional checklist of actual algae. PhD, Version 2.3 - third revision. Studii si Cercetări, Biologie, Universitatea Bacău 7(2002): 1-809.

Ciugulea I. \& TRIEmer R.E. 2010. A color atlas of photosynthetic euglenoids. Michigan State University Press, East Lansing.

Conforti V. \& Perez C. M. 2000. Euglenophyceae of Negro River, Uruguay, South America. Algol. Stud. 97: 59-78.

DEFLANDRE G. 1929. Observations sur les mouvements propres, pistes et vitesses de deplacement de quelques Protistes. Ann. Protist. 2: 1-40.

DILlaRD G. 1967. The freshwater algae of South Carolina, I. J. Elisha Mitchell Sci. Soc. 83: 128-132.

Dillard G. 2000. Freshwater Algae of the Southeastern United States. Part 7. Pigmented Euglenophyceae. J. Cramer, Stuttgart.

Dillard G. \& CRIDER S. 1970. Kentucky algae, part I. Trans. Kentucky Acad. Sci. 31: 66-72.

DuAngJan K. \& WoŁowsKi K. 2013. New taxa of loricate euglenoids Strombomonas and Trachelomonas from Thailand. Polish Bot. J. 58: 337-345.

DuAngJan K., Wolowski K. \& PeERAPORnPISAL Y. 2012. A taxonomic and ultrastructural study of Trachelomonas spp. (Euglenophyta) from agricultural area pond, Lamphun province. J. Microscopy Society of Thailand 5(1-2): 23-27.

ERSANLI E. \& GÖNÜLOL A. 2006. A study on the phytoplankton of Lake Simenit, Turkey. Cryptogamie, Algologie 27: 289-305.

Heckman C. W., Trindade B. R. S.\& Hardoim E. L. 1996. Environmental conditions in the Pantanal of Mato Grosso conductive to Natural euglenophyte populations. Japan J. Limnol. 57(2): 119-132.

Khondker M., Bhuiyan R.A., Yeasmin J., Alam M., SACK B., HuQ A. \& Colwell R. R. 2008. New records of phytoplankton for Bangladesh. 7. Phacus spp. Bangladesh J. Bot. 37(1): 55-60.

Kusel-FetzManN E. 2002. Die Euglenophytenflora des Neusiedler Sees (Burgenland, Österreich). Band $32 \mathrm{Ab}$ handlungen der Zoologisch-Botanischen Gesellschaft in Österreich, Wien.

LACKEY J. 1942. The plankton algae and protozoa of two Tennessee Rivers. Amer. Midl. Nat. 27: 191-202.

LACKEY J. 1958. The suspended microbiota of the Clinch River and adjacent Waters in relation to radioactivity in the summer of 1956. Engineering Progress at the University of Florida 12: 1-26.

LACKEY J. \& LACKEY E. 1967. A partial checklist of Florida freshwater algae and protozoa with reference to McCloud and Cue Lakes. Engineering Progress at the University of Florida 21: 1-28.

LeEdale G. F. 1967. Euglenoid flagellates. Prentice-Hall, Inc., London.

Linton E. W., KARNKOWSKA-ISHIKAWA A., Kim J. I., SHIN W., BenNetT M., KWIATOWSKI J., ZAKRYS B. \& TRIEMER R. E. 2010. Reconstructing euglenoid evolutionary relationships using three genes: nuclear SSU and LSU, and chloroplast $16 \mathrm{~S}$ rDNA sequences and the description of Euglenaria gen. nov. (Euglenophyta). Protist 161: 603-19.

Marin B., Palm A., Klingberg M. \& Melkonian M. 2003. Phylogeny and taxonomic revision of plastid-containing euglenophytes based on SSU rDNA sequence comparisons and synapomorphic signatures in the SSU rRNA secondary structure. Protist 154: 99-145.

McCoY J. 1967. Distribution of Euglenida in North Florida. Quart. J. Florida Acad. Sci. 29: 191-198.

MiLANOWSKi R., ZAKRYŚ B. \& KWIATOWSKI J. 2001. Phylogenetic analysis of chloroplast small subunit rRNA genes of the genus Euglena Ehrenberg. Int. J. Syst. Evol. Microbiol. 51: 783-791.

Milanowski R., Kosmala S., ZaKryś B. \& KWIATKOWSKi J. 2006. Phylogeny of photosynthetic euglenophytes based on combined chloroplast and cytoplasmic SSU rDNA sequence analysis. J. Phycol. 42: 721-730.

Morris F., THOMAS R., MORRIS M., Williams L., TAYLOR W., Hiatt F., Hern S., Hilgert J. \& LAmbou V. 1977. Distribution of phytoplankton in Georgia Lakes. U.S. Environ. Protection Agency, National Eutrophication Survey, Working Paper No. 680.

PATRICK C., CAIRnS J. JR. \& RobACK S. 1967. An ecosystematic study of the Savannah River. Proc. Acad. Nat. Sci. Philadelphia 118: 109-407. 
PochmanN 1941. Synopsis der Gattung Phacus. Arch. für Protisten. 95(1): 81-252.

PONIEWOZIK M. 2009. Taxonomical diversity within Trachelomonas genus in a former, small clay-pit. Fragm. Florist. Geobot. Polonica 16(2): 415-424.

Popova T. G. \& SAFONOVA T. A. 1976. Flora sporovych rastenij SSSR 9(2): 1-278. Evglenovye vodorosli (Euglenophyta). Izdatel'stvo "Nauka", Leningrad.

PRINGSHEIM E. G. 1956. Contributions towards a monograph of the genus Euglena. Nova Acta Leopoldiana 18: 3-168.

Ratha S. K., Jena M. \& Adhikary S. P. 2006. Euglenophytes from Orissa State, East Coast of India. Algae 21(1): 61-73.

Ratnasabapathy M. \& Deason T. 1977. Phytoplankton of the Black Warrior River, Alabama. Phytologia 37: 1-21.

Rosowski J. R. 2003. Photosynthetic euglenoids. In: J. D. WEHR \& R. G. SHEATH (eds), Freshwater algae of North America. Ecology and classification, pp. 383-422. Academic Press, New York.

SCHUMACHER G. \& WHITFORD L. 1961. Additions to the freshwater algae in North Carolina, VI. J. Elisha Mitchell Sci. Soc. 79: 22-26.

SMITH. R. 1958. Some additions to the freshwater algal flora of North Carolina: Algae occurring with Sphagnum. J. Elisha Mitchell Sci. Soc. 74: 158-160.

Taylor W., Hyatt F., Hern S., Hilgert J., Lambou V., MorRIS F., ThOMAS R., Morris M. \& Williams L. 1977. Distribution of phytoplankton in Florida lakes. U.S. Environ. Protection Agency, National Eutrophication Survey, Working Paper No. 679.

TELL G. \& CONFORTI V. 1986. Euglenophyta pigmentadas de la Argentina. Bibl. Phycolog. 75: 1-301.

TRIEMER R.E. \& FARMER M.A. 2007. A decade of euglenoid molecular phylogenetics. In: BRODIE J. \& LEWIS J. (eds) Unraveling the algae: the past, present and future of algal systematics. Systematics Association Series, CRC Press, Boca Raton, FL.

Vetrova Z. I. 2004. Flora algarum aquariorum continentalium Ucrainicae. Euglenophyta, Fasc. 2. Nacionalnaya Akademia Nauk Ukrainy, Kiev (in Russian). Whitford L.
1979. Additions to the freshwater algae in North Carolina, part 9. J. Elisha Mitchell Sci. Soc. 95: 42-47.

Williams L., Taylor W., Hiatt F., Hern S., Hilgert J., LAMBou V., Morris F., ThOMas R. \& Morris M. 1977. Distribution of phytoplankton in Mississippi lakes. U.S. Environ. Protection Agency, National Eutrophication Survey, Working Paper No. 685.

WOŁOWSKI K. 1989. Euglenophyta from the sewage treatment plant of the Kliny housing development in Cracow. Fragm. Florist. Geobot. 33(1/2): 219-226.

WoŁowsKi K. 1998. Taxonomic and environmental studies on euglenophytes of the Kraków-Częstochowa Upland (Southern Poland). Fragm. Florist. Geobot., Supplementum 6: 1-192.

WOŁOWSKI K. 2003. Euglenophytes reported from karst sinkholes in the Malopolska Upland (Poland, Central Europe). Annales de Limnologie - International Journal of Limnology 39: 333-346.

WoŁowsKi K. 2011. Phyllum Euglenophyta. In: D. M. JoHn, B. A. WhitTon \& A. J. BROOK (eds), The Freshwater Algal Flora of the British Isles: An Identification Guide to Freshwater and Terrestrial Algae, pp. 181-239. Cambridge University Press, Cambridge.

WoŁowsKi K. \& HindÁK F. 2005. Atlas of Euglenophytes. Veda, Publishing House of the Slovak Academy of Sciences.

WoŁowsKi K. \& WALNE P. L. 1997. Euglenophytes from Southeastern United States, I. Colorless species. Algol. Stud. 86: 109-135.

WolowsKi K. \& WALNE P. L. 2007. Strombomonas and Trachelomonas species (Euglenophyta) from south-eastern U.S.A. Eur. J. Phycol. 42(4): 409-431.

Woodson B. 1969. Algae of freshwater Virginia pond. Castanea 34: 352-374.

YAMAGiSHI T. 2010. Plankton algae of Southeast Asia. Bishen Singh Mahendra Pal Singh, India.

ZAKRYŚ B. \& WALNE P. L. 1994. Floristic, taxonomic and phytogeographic studies of green Euglenophyta from the Southeastern United States, with emphasis on new and rare species. Algol. Stud. 72: 71-114. 